\title{
Design, Synthesis, Biological Evaluation and Molecular Docking Studies of Some New Sulfonamides Possessing 1,4-Benzodioxane Nucleus
}

\author{
Misbah Irshad, ${ }^{1, \star}$ Muhammad Athar Abbasi, ${ }^{2}$ Aziz-Ur-Rehman, ${ }^{2}$ Qamar Ali, ${ }^{1}$ \\ Muhammad Aslam, ${ }^{1}$ Fozia Iram, ${ }^{3}$ Muhammad Shahid, ${ }^{4}$ Muhammad Ashraf, ${ }^{5}$ \\ Muhammad Arif Lodhi ${ }^{6}$ and Syed Babar Jamal ${ }^{7}$ \\ ${ }^{1}$ Department of Chemistry, Division of Science \& Technology, University of Education, Lahore-54770, Pakistan. \\ ${ }^{2}$ Department of Chemistry, Government College University, Lahore-54000, Pakistan. \\ ${ }^{3}$ Department of Chemistry, Lahore College for Women University, Lahore-75500, Pakistan \\ ${ }^{4}$ Department of Biochemistry, University of Agriculture, Faisalabad-38040, Pakistan. \\ ${ }^{5}$ Department of Pharmacy; The Islamia University of Bahawalpur, Bahawalpur-63100, Pakistan. \\ ${ }^{6}$ Department of Biochemistry, Abdul Wali Khan University, Mardan-23200, Pakistan. \\ ${ }^{7}$ Department of Bioinformatics, Islamic International University, Islamabad, Pakistan. \\ *Corresponding author: E-mail: misbahchatha@hotmail.com; misbahirshad@ue.edu.pk \\ Tel: (+92)-42-99262232
}

Received: 09-10-2018

\begin{abstract}
In the current research work we have reported a series of $\mathrm{N}$-aryl-2,3-dihydrobenzo[1,4]dioxine-6-sulfonamides 3 and their $\mathrm{N}$-substituted derivatives $\mathbf{6}$ and 7, obtained from 3 with benzyl chloride and ethyl iodide, respectively. The synthesis was accomplished as a multistep sequence. The structural confirmations were established by ${ }^{1} \mathrm{H}$ NMR, IR and EIMS spectral techniques. Butyrylcholinesterase (BChE), acetylcholinesterase (AChE) and lipoxygenase (LOX) enzymes were used in this study. It was observed that most of the compounds prepared exhibit a moderate activity against $\mathrm{BChE}$ and AChE but promisingly good activity against lipoxygenase. Among the parent sulfonamides $\mathbf{3 a}, \mathbf{3 b}, \mathbf{3} \mathbf{c}$ and $\mathbf{3 e}$ showed the proficient antimicrobial activities, while from the derivatives $6 \mathbf{a}, \mathbf{6 c}, 7 \mathbf{a}, 7 \mathbf{b}$ and $7 \mathbf{c}$ were found active against the selected panel of bacterial and fungal species. Hemolytic activity was also conducted to check their therapeutic utility. All the compounds were computationally docked against $\mathrm{LOX}, \mathrm{BChE}$ and $\mathrm{AChE}$ enzymes.
\end{abstract}

Keywords: 2,3-Dihydrobenzo[1,4] dioxine-6-sulfonyl chloride; lipoxygenase enzyme; antimicrobial and hemolytic activities; molecular docking.

\section{Introduction}

The very first prepared antimicrobial agents were sulfonamides, which are bacteriostatic agents and active against Gram negative and Gram positive bacteria. Basically, sulfonamides contain a benzene ring with sulfonyl and amino group at para position and have general formula $\mathrm{Ar} \mathrm{SO}_{2} \mathrm{NHR}$. The nature of $\mathrm{Arl}$ and $\mathrm{R}$ varies from simple hydrogen to aliphatic carboaromatic, heterocyclic, $\mathrm{OH}$,
$\mathrm{NH}_{2}$ or sugar scaffolds. SAR studies revealed that the liberated $\mathrm{NH}_{2}$ group of sulfonamides is responsible for their activity. Low activity was observed in the case of attached substituents at ortho and meta positions. ${ }^{1-5}$ Sulfonamides restrain folic acid in bacteria which facilitates the production of bacterial DNA and RNA. Dihydropteroic acid is precursor of folic acid. Dihydropteroate synthase is responsible for the transformation of dihydropteroate diphosphate and $P$-aminobenzoic acid into dihydropteroic 
acid; on the other hand, sulfonamides hinder this enzyme. ${ }^{6,7}$ These sulfonamide drugs can be classified as oral (absorbed and unabsorbed) and topical. Depending on the action absorbable sulfonamides can be short-, intermediate- and long-acting. Their absorption takes place through stomach and small intestine. ${ }^{8}$ Commonly these sulfa drugs are synthesized by treating substituted sulfonyl chloride with suitable amine compounds. Sulfonamides are used to cure membrane infections, enteritis, ulcerative colitis and for skin treatments. In agriculture sulfonamides have antiherbicidal and antifungal uses. They have wide applications as antiobesity, ${ }^{9}$ anticancer, antiviral, ${ }^{3}$ protease inhibitors, ${ }^{10}$ diuretic, ${ }^{11,12}$ hypoglycemic, ${ }^{13}$ antithyroid, ${ }^{14}$ antitumor, ${ }^{15-17}$ anti-neuropathic pain, ${ }^{18}$ antibacterial, ${ }^{19,20}$ cyclooxygenase $^{21}$ and carbonic anhydrase inhibitory agents. ${ }^{22}$

Compounds containing a 1,4-benzodioxane skeleton display wider range of biological activities ${ }^{23}$ such as anticancer, ${ }^{24,25}$ immunosuppressive, ${ }^{26}$ antiinflammatory, ${ }^{27}$ antibacterial ${ }^{28}$ and some others. ${ }^{29,30}$

Additionally, interaction modes of the synthesized compounds were examined by molecular docking approach. The purpose of docking methodologies was to forecast the ligand and target complex and to align the molecular database (designed inhibitors) on the basis of binding affinity to that of target. The MOE-Dock was used for docking of all the synthesized inhibitors with the binding site of target enzymes. The eventual objective of molecular docking was to get ligands with better characteristics displaying good inhibition potential. ${ }^{31}$ This research work is a productive effort to bring in close proximity the pharmacologically significant moieties. Keeping continuity in connection with the research work on sulfonamide molecules, ${ }^{32}$ the different $\mathrm{N}$-substituted sulfonamides derived from 1,4-benzodioxine-6-sulfonyl chloride were synthesized. It was aimed that the new drugs bearing sulfamoyl functionality would have striking activity and be able to cope with the challenges.

\section{Experimental}

\section{1. General}

2,3-Dihydrobenzo[1,4]dioxine-6-sulfonyl chloride, different aryl amines and the other electrophilic reagents were purchased from local suppliers of chemicals. All the solvents were used after distillation and purification. Griffin and George melting point instrument was employed to record melting points of the target compounds. The open capillary tube was used and melting points are reported uncorrected. The TLC was utilized to check the purity and reaction progress. TLC plates were finished from pre-coated silica gel G-25- $\mathrm{UV}_{254}$. The gradient solvent systems of ethyl acetate $\left(\mathrm{C}_{4} \mathrm{H}_{8} \mathrm{O}_{2}\right)$ and $n$-hexane $\left(\mathrm{C}_{6} \mathrm{H}_{14}\right)$ were applied. The detection was carried out at $254 \mathrm{~nm}$ and TLC plates were developed by ceric sulphate reagent. On a Jasco-320-A spectrophotometer the IR spectra were record- ed. The pellet of a sample was made with $\mathrm{KBr}$ and functional group stretchings are reported in wave numbers $\left(\mathrm{cm}^{-1}\right)$. NMR spectra were recorded on Bruker spectrometers. The deutrated methanol and chloroform were used as the solvents. The operating frequencies thus utilized were 300 and $400 \mathrm{MHz}$ and chemical shifts are given in ppm. On a JMS-HX-110 spectrometer the mass spectra (EIMS) were measured with a data system.

\section{2. Synthesis}

\section{2. 1. General Procedure for the Synthesis of $N$-Aryl-2,3-dihydrobenzo[1,4] dioxine-6- sulfonamides (3a-e) in Aqueous Medium}

$0.85 \mathrm{mmol}$ of various substituted aryl amines $\mathbf{2 a}-\mathbf{e}$ were dispensed in $50 \mathrm{~mL}$ of distilled water contained in a $250 \mathrm{~mL}$ round-bottom flask. The $\mathrm{pH}$ of the reacting medium was maintained at 9.0-10.0. The aqueous solution of $\mathrm{Na}_{2} \mathrm{CO}_{3}$ was added drop wise at $25^{\circ} \mathrm{C}$. Subsequently 0.85 $\mathrm{mmol}(0.20 \mathrm{~g})$ of 2,3-dihydrobenzo[1,4] dioxine-6-sulfonyl chloride (1) was added slowly to the reaction mass over 10-15 min. The reaction mixture was kept on stirring at RT till the TLC confirmation indicated the completion of the reaction. The workup was done by slowly adding conc. aq. $\mathrm{HCl}(2 \mathrm{~mL})$ and dropping $\mathrm{pH}$ to 2.0. The title compounds $3 \mathbf{a}-\mathbf{e}$ were collected as solid precipitates on filtration and washed with immense volume of distilled water.

\section{$N$-(2,3-Dimethylphenyl)-2,3-dihydrobenzo[1,4]diox-} ine-6-sulfonamide (3a)

White solid; yield: $80 \%$ (217.7 mg); m.p. $102-104{ }^{\circ} \mathrm{C}$; molecular formula: $\mathrm{C}_{16} \mathrm{H}_{17} \mathrm{NO}_{4} \mathrm{~S}$; molecular weight: $319 \mathrm{~g} /$ mol; HR-MS: $[\mathrm{M}]^{+} 319.3772$ (Calcd. for $\mathrm{C}_{16} \mathrm{H}_{17} \mathrm{NO}_{4} \mathrm{~S}$; 319.3854); IR $\left(\mathrm{KBr}, \mathrm{cm}^{-1}\right)$ : $v_{\max }$ stretching: $3419(\mathrm{~N}-\mathrm{H})$, 3026 (C-H Ar ring), $2914\left(\mathrm{CH}_{2}\right), 1613(\mathrm{C}=\mathrm{C}$ Ar ring), $1325\left(\mathrm{SO}_{2}\right), 1125$ (C-O-C of ether); ${ }^{1} \mathrm{H}$ NMR (400 MHz,C$\mathrm{DCl}_{3}$ ): $\delta$ (ppm) 1.99 (s, 3H, $\mathrm{CH}_{3}-2$ "), 2.27 (s, 3H, $\mathrm{CH}_{3}-1$ "), 4.24-4.27 (m, $\left.4 \mathrm{H}, \mathrm{CH}_{2}-2, \mathrm{CH}_{2}-3\right), 6.73$ (brd, $J=7.6 \mathrm{~Hz}$, $\left.1 \mathrm{H}, \mathrm{H}-4^{\prime}\right), 6.78\left(\mathrm{t}, J=7.6 \mathrm{~Hz}, 1 \mathrm{H}, \mathrm{H}-5^{\prime}\right), 6.80(\mathrm{~d}, J=8.0 \mathrm{~Hz}$, $\left.1 \mathrm{H}, \mathrm{H}-6^{\prime}\right), 6.95(\mathrm{~d}, J=8.4 \mathrm{~Hz}, 1 \mathrm{H}, \mathrm{H}-8), 7.18\left(\mathrm{dd}, J_{1}=8.4\right.$ $\left.\mathrm{Hz}, J_{2}=2.0 \mathrm{~Hz}, 1 \mathrm{H}, \mathrm{H}-7\right), 7.25(\mathrm{~d}, J=2.0 \mathrm{~Hz}, 1 \mathrm{H}, \mathrm{H}-5)$;

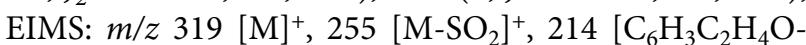
$\left.{ }_{2} \mathrm{SO}_{2} \mathrm{NH}\right]^{+}, 199\left[\mathrm{C}_{6} \mathrm{H}_{3} \mathrm{C}_{2} \mathrm{H}_{4} \mathrm{O}_{2} \mathrm{SO}_{2}\right]^{+}, 135\left[\mathrm{C}_{6} \mathrm{H}_{3} \mathrm{C}_{2} \mathrm{H}_{4} \mathrm{O}_{2}\right]^{+}$, $107\left[\mathrm{C}_{6} \mathrm{H}_{3} \mathrm{O}_{2}\right]^{+}, 105\left[\mathrm{C}_{6} \mathrm{H}_{3}\left(\mathrm{CH}_{3}\right)_{2}\right]^{+}, 90\left[\mathrm{C}_{6} \mathrm{H}_{3} \mathrm{CH}_{3}\right]^{+}, 79$ $\left[\mathrm{C}_{4} \mathrm{H}\left(\mathrm{CH}_{3}\right)_{2}\right]^{+}, 75\left[\mathrm{C}_{6} \mathrm{H}_{3}\right]^{+}, 64\left[\mathrm{C}_{4} \mathrm{HCH}_{3}\right]^{+}$.

\section{$N$-(2,4-Dimethylphenyl)-2,3-dihydrobenzo[1,4]diox- ine-6-sulfonamide (3b) \\ White solid; yield: $89 \%$ (242.2 mg); m.p. $108-110^{\circ} \mathrm{C}$; molecular formula: $\mathrm{C}_{16} \mathrm{H}_{17} \mathrm{NO}_{4} \mathrm{~S}$; molecular weight: $319 \mathrm{~g} /$ mol; HR-MS: $[\mathrm{M}]^{+} 319.3772$ (Calcd. for $\mathrm{C}_{16} \mathrm{H}_{17} \mathrm{NO}_{4} \mathrm{~S}$; 319.3854); IR $\left(\mathrm{KBr}, \mathrm{cm}^{-1}\right)$ : $v_{\max }$ stretching: $3435(\mathrm{~N}-\mathrm{H})$, 3021 (C-H Ar ring), $2917\left(-\mathrm{CH}_{2}-\right), 1615$ (C=C Ar ring), $1324\left(-\mathrm{SO}_{2}-\right), 1140$ (C-O-C of ether); ${ }^{1} \mathrm{H}$ NMR $(400 \mathrm{MHz}$, $\left.\mathrm{CDCl}_{3}\right): \delta(\mathrm{ppm}) 1.99$ (s, 3H, $\mathrm{CH}_{3}-2$ "), $2.24\left(\mathrm{~s}, 3 \mathrm{H}, \mathrm{CH}_{3}-\right.$ 1"), 4.24-4.26 (m, $\left.4 \mathrm{H}, \mathrm{CH}_{2}-2, \mathrm{CH}_{2}-3\right), 6.80\left(\mathrm{~s}, 1 \mathrm{H}, \mathrm{H}-3^{\prime}\right)$,}


$6.84\left(\mathrm{~d}, J=8.0 \mathrm{~Hz}, 1 \mathrm{H}, \mathrm{H}-5^{\prime}\right), 6.92\left(\mathrm{~d}, J=8.4 \mathrm{~Hz}, 1 \mathrm{H}, \mathrm{H}-6^{\prime}\right)$, $7.12(\mathrm{~d}, J=8.0 \mathrm{~Hz}, 1 \mathrm{H}, \mathrm{H}-8), 7.17\left(\mathrm{dd}, J_{1}=8.4 \mathrm{~Hz}, J_{2}=2.0\right.$ $\mathrm{Hz}, 1 \mathrm{H}, \mathrm{H}-7), 7.26$ (d, $J=2.0 \mathrm{~Hz}, 1 \mathrm{H}, \mathrm{H}-5$ ); EIMS: $m / z 319$ $[\mathrm{M}]^{+}, 255\left[\mathrm{M}-\mathrm{SO}_{2}\right]^{+}, 214\left[\mathrm{C}_{6} \mathrm{H}_{3} \mathrm{C}_{2} \mathrm{H}_{4} \mathrm{O}_{2} \mathrm{SO}_{2} \mathrm{NH}\right]^{+}, 199$ $\left[\mathrm{C}_{6} \mathrm{H}_{3} \mathrm{C}_{2} \mathrm{H}_{4} \mathrm{O}_{2} \mathrm{SO}_{2}\right]^{+}, 135\left[\mathrm{C}_{6} \mathrm{H}_{3} \mathrm{C}_{2} \mathrm{H}_{4} \mathrm{O}_{2}\right]^{+}, 107\left[\mathrm{C}_{6} \mathrm{H}_{3} \mathrm{O}_{2}\right]^{+}$, $105\left[\mathrm{C}_{6} \mathrm{H}_{3}\left(\mathrm{CH}_{3}\right)_{2}\right]^{+}, 90\left[\mathrm{C}_{6} \mathrm{H}_{3} \mathrm{CH}_{3}\right]^{+}, 79\left[\mathrm{C}_{4} \mathrm{H}\left(\mathrm{CH}_{3}\right)_{2}\right]^{+}, 75$ $\left[\mathrm{C}_{6} \mathrm{H}_{3}\right]^{+}, 64\left[\mathrm{C}_{4} \mathrm{HCH}_{3}\right]^{+}$.

\section{$N$-(2,5-Dimethylphenyl)-2,3-dihydrobenzo[1,4] diox- ine-6-sulfonamide (3c)}

White solid; yield: $82 \%$ (223.1 mg); m.p. $124-126^{\circ} \mathrm{C}$; molecular formula: $\mathrm{C}_{16} \mathrm{H}_{17} \mathrm{NO}_{4} \mathrm{~S}$; molecular weight: $319 \mathrm{~g} /$ mol; HR-MS: $[\mathrm{M}]^{+} 319.3772$ (Calcd. for $\mathrm{C}_{16} \mathrm{H}_{17} \mathrm{NO}_{4} \mathrm{~S}$; 319.3854); IR $\left(\mathrm{KBr}, \mathrm{cm}^{-1}\right): v_{\max }$ stretching: $3415(\mathrm{~N}-\mathrm{H})$, 3024 (C-H Ar ring), $2912\left(-\mathrm{CH}_{2}-\right), 1619$ (C=C Ar ring), $1325\left(-\mathrm{SO}_{2}-\right), 1122$ (C-O-C of ether); ${ }^{1} \mathrm{H}$ NMR $(300 \mathrm{MHz}$, $\left.\mathrm{CD}_{3} \mathrm{OD}\right): \delta(\mathrm{ppm}) 1.96$ (s, $3 \mathrm{H}, \mathrm{CH}_{3}-2$ "), $2.20\left(\mathrm{~s}, 3 \mathrm{H}, \mathrm{CH}_{3}-\right.$ 1"), $4.22-4.30\left(\mathrm{~m}, 4 \mathrm{H}, \mathrm{CH}_{2}-2, \mathrm{CH}_{2}-3\right), 6.85(\mathrm{~d}, J=7.6 \mathrm{~Hz}$, $1 \mathrm{H}, \mathrm{H}-4^{\prime}$ ), 6.89 (d, J = 7.5 Hz, 1H, H-3'), 6.91 (s, 1H, H-6'), $6.99(\mathrm{~d}, J=8.1 \mathrm{~Hz}, 1 \mathrm{H}, \mathrm{H}-8), 7.09(\mathrm{~d}, J=2.1 \mathrm{~Hz}, 1 \mathrm{H}, \mathrm{H}-5)$, $7.13\left(\mathrm{dd}, J_{1}=7.8 \mathrm{~Hz}, J_{2}=2.1 \mathrm{~Hz}, 1 \mathrm{H}, \mathrm{H}-7\right.$ ); EIMS: $m / z 319$

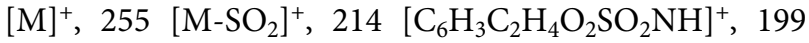
$\left[\mathrm{C}_{6} \mathrm{H}_{3} \mathrm{C}_{2} \mathrm{H}_{4} \mathrm{O}_{2} \mathrm{SO}_{2}\right]^{+}, 135\left[\mathrm{C}_{6} \mathrm{H}_{3} \mathrm{C}_{2} \mathrm{H}_{4} \mathrm{O}_{2}\right]^{+}, 107\left[\mathrm{C}_{6} \mathrm{H}_{3} \mathrm{O}_{2}\right]^{+}$, $105\left[\mathrm{C}_{6} \mathrm{H}_{3}\left(\mathrm{CH}_{3}\right)_{2}\right]^{+}, 90\left[\mathrm{C}_{6} \mathrm{H}_{3} \mathrm{CH}_{3}\right]^{+}, 79\left[\mathrm{C}_{4} \mathrm{H}\left(\mathrm{CH}_{3}\right)_{2}\right]^{+}, 75$ $\left[\mathrm{C}_{6} \mathrm{H}_{3}\right]^{+}, 64\left[\mathrm{C}_{4} \mathrm{HCH}_{3}\right]^{+}$.

\section{$N$-(2,6-Dimethylphenyl)-2,3-dihydrobenzo[1,4] diox- ine-6-sulfonamide (3d)}

White solid; yield: 71\% (193.2 mg); m.p. 151-153 ${ }^{\circ} \mathrm{C}$; molecular formula: $\mathrm{C}_{16} \mathrm{H}_{17} \mathrm{NO}_{4} \mathrm{~S}$; molecular weight: 319 g/mol; HR-MS: $[\mathrm{M}]^{+} 319.3772$ (Calcd. for $\mathrm{C}_{16} \mathrm{H}$ ${ }_{17} \mathrm{NO}_{4} \mathrm{~S}$; 319.3854); IR $\left(\mathrm{KBr}, \mathrm{cm}^{-1}\right): v_{\max }$ stretching: 3410 $(\mathrm{N}-\mathrm{H}), 3045$ (C-H Ar ring), $2909\left(-\mathrm{CH}_{2^{-}}\right), 1614(\mathrm{C}=\mathrm{C})$, $1326\left(-\mathrm{SO}_{2}-\right), 1125$ (C-O-C of ether); ${ }^{1} \mathrm{H}$ NMR $(300 \mathrm{MHz}$, $\mathrm{CDCl}_{3}$ ): $\delta$ (ppm) 2.02 (s, $6 \mathrm{H}, \mathrm{CH}_{3}-1$ ", $\mathrm{CH}_{3}-2$ "), 4.25-4.30 (m, $4 \mathrm{H}, \mathrm{CH}_{2}-2, \mathrm{CH}_{2}-3$ ), 6.93 (brd, $J=7.8 \mathrm{~Hz}, 1 \mathrm{H}, \mathrm{H}-4^{\prime}$ ), 7.01 (d, $J=8.4 \mathrm{~Hz}, 2 \mathrm{H}, \mathrm{H}-3$ ', H-5'), 7.03 (d, $J=8.4 \mathrm{~Hz}, 1 \mathrm{H}$, $\mathrm{H}-8), 7.38(\mathrm{~d}, J=2.4 \mathrm{~Hz}, 1 \mathrm{H}, \mathrm{H}-5), 7.48\left(\mathrm{dd}, J_{1}=8.4 \mathrm{~Hz}, J_{2}\right.$ $=2.4 \mathrm{~Hz}, 1 \mathrm{H}, \mathrm{H}-7)$; EIMS: $m / z 319[\mathrm{M}]^{+}, 255\left[\mathrm{M}-S O_{2}\right]^{+}$, $214\left[\mathrm{C}_{6} \mathrm{H}_{3} \mathrm{C}_{2} \mathrm{H}_{4} \mathrm{O}_{2} \mathrm{SO}_{2} \mathrm{NH}\right]^{+}, 199\left[\mathrm{C}_{6} \mathrm{H}_{3} \mathrm{C}_{2} \mathrm{H}_{4} \mathrm{O}_{2} \mathrm{SO}_{2}\right]^{+}, 135$ $\left[\mathrm{C}_{6} \mathrm{H}_{3} \mathrm{C}_{2} \mathrm{H}_{4} \mathrm{O}_{2}\right]^{+}, 107\left[\mathrm{C}_{6} \mathrm{H}_{3} \mathrm{O}_{2}\right]^{+}, 105\left[\mathrm{C}_{6} \mathrm{H}_{3}\left(\mathrm{CH}_{3}\right)_{2}\right]^{+}, 90$ $\left[\begin{array}{lllll}\left.\mathrm{C}_{6} \mathrm{H}_{3} \mathrm{CH}_{3}\right]^{+}, & 79 & {\left[\mathrm{C}_{4} \mathrm{H}\left(\mathrm{CH}_{3}\right)_{2}\right]^{+},} & 75 & {\left[\mathrm{C}_{6} \mathrm{H}_{3}\right]^{+},}\end{array}\right.$ $\left[\mathrm{C}_{4} \mathrm{HCH}_{3}\right]^{+}$.

\section{$N$-(3,4-Dimethylphenyl)-2,3-dihydrobenzo[1,4] diox- ine-6-sulfonamide (3e)}

White solid; yield: $86 \%$ (234.0 mg); m.p. $124-126^{\circ} \mathrm{C}$; molecular formula: $\mathrm{C}_{16} \mathrm{H}_{17} \mathrm{NO}_{4} \mathrm{~S}$; molecular weight: $319 \mathrm{~g} /$ mol; HR-MS: $[\mathrm{M}]^{+} 319.3772$ (Calcd. for $\mathrm{C}_{16} \mathrm{H}_{17} \mathrm{NO}_{4} \mathrm{~S}$; 319.3854); IR $\left(\mathrm{KBr}, \mathrm{cm}^{-1}\right): v_{\max }$ stretching: $3422(\mathrm{~N}-\mathrm{H})$, 3018 (C-H Ar ring), $2919\left(-\mathrm{CH}_{2}-\right), 1615$ ( $\mathrm{C}=\mathrm{C}$ Ar ring), $1323\left(-\mathrm{SO}_{2}\right), 1118$ (C-O-C of ether); ${ }^{1} \mathrm{H}$ NMR (400 $\mathrm{MHz}, \mathrm{CDCl}_{3}$ ): $\delta$ (ppm) 2.15 (s, $6 \mathrm{H}, \mathrm{CH}_{3}-1$ ", $\mathrm{CH}_{3}-2$ "), $4.23-$ $4.25\left(\mathrm{~m}, 4 \mathrm{H}, \mathrm{CH}_{2}-2, \mathrm{CH}_{2}-3\right), 6.76\left(\mathrm{~d}, J=7.6 \mathrm{~Hz}, 1 \mathrm{H}, \mathrm{H}-5^{\prime}\right)$, $6.81\left(\mathrm{~s}, 1 \mathrm{H}, \mathrm{H}-2^{\prime}\right), 6.84\left(\mathrm{~d}, J=8.0 \mathrm{~Hz}, 1 \mathrm{H}, \mathrm{H}-6^{\prime}\right), 6.96(\mathrm{~d}, J$ $=8.0 \mathrm{~Hz}, 1 \mathrm{H}, \mathrm{H}-8), 7.22\left(\mathrm{dd}, J_{1}=8.4 \mathrm{~Hz}, J_{2}=2.0 \mathrm{~Hz}, 1 \mathrm{H}\right.$,
H-7), 7.28 (d, $J=2.0 \mathrm{~Hz}, 1 \mathrm{H}, \mathrm{H}-5$ ); EIMS: $m / z 319[\mathrm{M}]^{+}$, $255\left[\mathrm{M}-\mathrm{SO}_{2}\right]^{+}, 214\left[\mathrm{C}_{6} \mathrm{H}_{3} \mathrm{C}_{2} \mathrm{H}_{4} \mathrm{O}_{2} \mathrm{SO}_{2} \mathrm{NH}\right]^{+}, 199\left[\mathrm{C}_{6} \mathrm{H}-\right.$ $\left.{ }_{3} \mathrm{C}_{2} \mathrm{H}_{4} \mathrm{O}_{2} \mathrm{SO}_{2}\right]^{+}, 135\left[\mathrm{C}_{6} \mathrm{H}_{3} \mathrm{C}_{2} \mathrm{H}_{4} \mathrm{O}_{2}\right]^{+}, 107\left[\mathrm{C}_{6} \mathrm{H}_{3} \mathrm{O}_{2}\right]^{+}, 105$ $\left[\mathrm{C}_{6} \mathrm{H}_{3}\left(\mathrm{CH}_{3}\right)_{2}\right]^{+}, 90\left[\mathrm{C}_{6} \mathrm{H}_{3} \mathrm{CH}_{3}\right]^{+}, 79\left[\mathrm{C}_{4} \mathrm{H}\left(\mathrm{CH}_{3}\right)_{2}\right]^{+}, 75$ $\left[\mathrm{C}_{6} \mathrm{H}_{3}\right]^{+}, 64\left[\mathrm{C}_{4} \mathrm{HCH}_{3}\right]^{+}$.

\section{2. 2. General Procedure for the Synthesis of Compounds 6a-e and 7a-e}

$0.40 \mathrm{mmol}(0.01 \mathrm{~g})$ of lithum hydride was added to a solution containing of $0.1 \mathrm{~g}$ of compounds $3 \mathbf{a}-\mathbf{e}$ in $25 \mathrm{~mL}$ of aprotic solvent (DMF) and kept in round-bottom flask at $25^{\circ} \mathrm{C}$. On complete addition, the reaction mixture was stirred for half an hour. The benzyl chloride (4) and ethyl iodide (5) were added into the reaction mixture to establish $\mathbf{6 a}-\mathbf{e}$ and $7 \mathbf{a}-\mathbf{e}$ series, respectively. The stirring lasted for 1-2 $\mathrm{h}$. The monitoring of the reaction completion was done by TLC. The reaction contents were quenched with cold distilled water after ensuring the complete conversion of the reactants. The corresponding $\mathrm{N}$-benzyl/ethyl derivatives of $\mathrm{N}$-aryl-2,3-dihydrobenzo[1,4]dioxine-6-sulfonamides $\mathbf{6 a}-\mathbf{e}$ and $7 \mathbf{a}-\mathbf{e}$ were obtained as solid precipitates on filtration. The subsequent washing with distilled water and drying yielded our target molecules. The greasy and sticky compounds were isolated through solvent extraction by using chloroform.

\section{$N$-Benzyl- $N$-(2,3-dimethylphenyl)-2,3-dihydrobenzo $[1,4]$ dioxine-6-sulfonamide (6a) \\ Yellow sticky solid; yield: $86 \%$ (110.3 mg); molecular} formula: $\mathrm{C}_{23} \mathrm{H}_{23} \mathrm{NO}_{4} \mathrm{~S}$; molecular weight: $409 \mathrm{~g} / \mathrm{mol}$; HRMS: $[\mathrm{M}]^{+} 409.4991$ (Calcd. for $\mathrm{C}_{23} \mathrm{H}_{23} \mathrm{NO}_{4} \mathrm{~S}$; 409.5187); IR $\left(\mathrm{KBr}, \mathrm{cm}^{-1}\right): v_{\max }$ stretching: $3416(\mathrm{~N}-\mathrm{H}), 3015(\mathrm{C}-\mathrm{H} \mathrm{Ar}$ ring), $2918\left(-\mathrm{CH}_{2}-\right), 1617\left(\mathrm{C}=\mathrm{C}\right.$ Ar ring), $1329\left(-\mathrm{SO}_{2}-\right)$, 1135 (C-O-C of ether); ${ }^{1} \mathrm{H}$ NMR (400 MHz, $\left.\mathrm{CD}_{3} \mathrm{OD}\right): \delta$ (ppm) 2.00 (s, 3H, $\mathrm{CH}_{3}-2$ "'), 2.06 (s, 3H, $\mathrm{CH}_{3}-1$ "'), 4.25 4.29 (m, $\left.4 \mathrm{H}, \mathrm{CH}_{2}-2, \mathrm{CH}_{2}-3\right), 4.63$ (s, $\left.2 \mathrm{H}, \mathrm{CH}_{2}-7^{\prime \prime}\right), 6.81$ (d, $J=7.6 \mathrm{~Hz}, 1 \mathrm{H}, \mathrm{H}-4$ '), $6.87-6.95$ (m, $5 \mathrm{H}, \mathrm{H}-2$ " to $\mathrm{H}-6$ "), $7.02\left(\mathrm{~d}, J=7.2 \mathrm{~Hz}, 1 \mathrm{H}, \mathrm{H}-6^{\prime}\right), 7.10\left(\mathrm{t}, J=7.6 \mathrm{~Hz}, 1 \mathrm{H}, \mathrm{H}-5^{\prime}\right)$, $7.31(\mathrm{~d}, J=8.4 \mathrm{~Hz}, 1 \mathrm{H}, \mathrm{H}-8), 7.34(\mathrm{~d}, J=2.0 \mathrm{~Hz}, 1 \mathrm{H}, \mathrm{H}-5)$, 7.38 (dd, $J_{1}=8.4 \mathrm{~Hz}, J_{2}=2.0 \mathrm{~Hz}, 1 \mathrm{H}, \mathrm{H}-7$ ); EIMS: $m / z 409$ $[\mathrm{M}]^{+}, 345\left[{\mathrm{M}-\mathrm{SO}_{2}}^{+}\right]^{+}, 304\left[\mathrm{C}_{6} \mathrm{H}_{3} \mathrm{C}_{2} \mathrm{H}_{4} \mathrm{O}_{2} \mathrm{SO}_{2} \mathrm{NCH}_{2} \mathrm{C}_{6} \mathrm{H}_{5}\right]^{+}$, $199 \quad\left[\mathrm{C}_{6} \mathrm{H}_{3} \mathrm{C}_{2} \mathrm{H}_{4} \mathrm{O}_{2} \mathrm{SO}_{2}\right]^{+}, 135 \quad\left[\mathrm{C}_{6} \mathrm{H}_{3} \mathrm{C}_{2} \mathrm{H}_{4} \mathrm{O}_{2}\right]^{+}, 107$ $\left[\mathrm{C}_{6} \mathrm{H}_{3} \mathrm{O}_{2}\right]^{+}, 105\left[\mathrm{C}_{6} \mathrm{H}_{3}\left(\mathrm{CH}_{3}\right)_{2}\right]^{+}, 91\left[\mathrm{C}_{7} \mathrm{H}_{7}\right]^{+}, 90\left[\mathrm{C}_{6} \mathrm{H}_{3}\right.$ $\left.\mathrm{CH}_{3}\right]^{+}, 79\left[\mathrm{C}_{4} \mathrm{H}\left(\mathrm{CH}_{3}\right)_{2}\right]^{+}, 75\left[\mathrm{C}_{6} \mathrm{H}_{3}\right]^{+}, 65\left[\mathrm{C}_{5} \mathrm{H}_{5}\right]^{+}, 64$ $\left[\mathrm{C}_{4} \mathrm{HCH}_{3}\right]^{+}$.

\section{$N$-Benzyl- $N$-(2,4-dimethylphenyl)-2,3-dihydrobenzo $[1,4]$ dioxine-6-sulfonamide (6b)}

Light grey sticky solid; yield: 78\% (100.0 mg); molecular formula: $\mathrm{C}_{23} \mathrm{H}_{23} \mathrm{NO}_{4} \mathrm{~S}$; molecular weight: $409 \mathrm{~g} / \mathrm{mol}$; HR-MS: $[\mathrm{M}]^{+} 409.4991$ (Calcd. for $\mathrm{C}_{23} \mathrm{H}_{23} \mathrm{NO}_{4} \mathrm{~S}$; 409.5187); IR $\left(\mathrm{KBr}, \mathrm{cm}^{-1}\right)$ : $v_{\max }$ stretching: $3423(\mathrm{~N}-\mathrm{H})$, 3067 (C-H Ar ring), $2932\left(-\mathrm{CH}_{2}-\right), 1617$ (C=C Ar ring), $1326\left(-\mathrm{SO}_{2}\right), 1145$ (C-O-C of ether); ${ }^{1} \mathrm{H}$ NMR (300 $\mathrm{MHz}, \mathrm{CD}_{3} \mathrm{OD}$ ): $\delta$ (ppm) 1.90 (s, 3H, $\mathrm{CH}_{3}-2$ "'), 2.22 (s, $3 \mathrm{H}$, 
$\left.\mathrm{CH}_{3}-1^{\prime \prime \prime}\right), 4.19$ (s, 2H, $\mathrm{CH}_{2}-7$ ") , 4.32-4.34 (m, 4H, $\mathrm{CH}_{2}-2$, $\left.\mathrm{CH}_{2}-3\right), 6.55$ (d, $J=8.1 \mathrm{~Hz}, 1 \mathrm{H}, \mathrm{H}-5$ '), 6.86 (d, $J=7.8 \mathrm{~Hz}$, $1 \mathrm{H}, \mathrm{H}-6$ '), 6.90 (s, 1H, H-3'), 6.92-7.01 (m, 5H, H-2” to H-6”), 7.10 (d, J=8.1 Hz, 1H, H-8), 7.17 (d, J=2.1 Hz, 1H, $\mathrm{H}-5), 7.19$ (dd, $J_{1}=8.1 \mathrm{~Hz}, J_{2}=2.1 \mathrm{~Hz}, 1 \mathrm{H}, \mathrm{H}-7$ ); EIMS: $m / z 409[\mathrm{M}]^{+}, 345\left[\mathrm{M}-\mathrm{SO}_{2}\right]^{+}, 304\left[\mathrm{C}_{6} \mathrm{H}_{3} \mathrm{C}_{2} \mathrm{H}_{4} \mathrm{O}_{2} \mathrm{SO}_{2} \mathrm{~N}-\right.$ $\left.\mathrm{CH}_{2} \mathrm{C}_{6} \mathrm{H}_{5}\right]^{+}, 199\left[\mathrm{C}_{6} \mathrm{H}_{3} \mathrm{C}_{2} \mathrm{H}_{4} \mathrm{O}_{2} \mathrm{SO}_{2}\right]^{+}, 135\left[\mathrm{C}_{6} \mathrm{H}_{3} \mathrm{C}_{2} \mathrm{H}_{4} \mathrm{O}_{2}\right]^{+}$, $107 \quad\left[\mathrm{C}_{6} \mathrm{H}_{3} \mathrm{O}_{2}\right]^{+}, 105 \quad\left[\mathrm{C}_{6} \mathrm{H}_{3}\left(\mathrm{CH}_{3}\right)_{2}\right]^{+}, 91 \quad\left[\mathrm{C}_{7} \mathrm{H}_{7}\right]^{+}, 90$ $\left[\mathrm{C}_{6} \mathrm{H}_{3} \mathrm{CH}_{3}\right]^{+}, 79\left[\mathrm{C}_{4} \mathrm{H}\left(\mathrm{CH}_{3}\right)_{2}\right]^{+}, 75\left[\mathrm{C}_{6} \mathrm{H}_{3}\right]^{+}, 65\left[\mathrm{C}_{5} \mathrm{H}_{5}\right]^{+}, 64$ $\left[\mathrm{C}_{4} \mathrm{HCH}_{3}\right]^{+}$.

\section{$N$-Benzyl- $N$-(2,5-dimethylphenyl)-2,3-dihydrobenzo $[1,4]$ dioxine-6-sulfonamide $(6 \mathrm{c})$}

Yellow sticky solid; yield: 76\% (97.4 mg); molecular formula: $\mathrm{C}_{23} \mathrm{H}_{23} \mathrm{NO}_{4} \mathrm{~S}$; molecular weight: $409 \mathrm{~g} / \mathrm{mol}$; HRMS: $[\mathrm{M}]^{+} 409.4991$ (Calcd. for $\mathrm{C}_{23} \mathrm{H}_{23} \mathrm{NO}_{4} \mathrm{~S}$; 409.5187); IR $\left(\mathrm{KBr}, \mathrm{cm}^{-1}\right): v_{\max }$ stretching: $3431(\mathrm{~N}-\mathrm{H}), 3041(\mathrm{C}-\mathrm{H} \mathrm{Ar}$ ring), $2922\left(-\mathrm{CH}_{2}-\right), 1612\left(\mathrm{C}=\mathrm{C}\right.$ Ar ring), $1328\left(-\mathrm{SO}_{2}^{-}\right)$, 1131 (C-O-C of ether); ${ }^{1} \mathrm{H}$ NMR (300 MHz, $\left.\mathrm{CD}_{3} \mathrm{OD}\right): \delta$ (ppm) 1.89 (s, 3H, $\mathrm{CH}_{3}-2$ "'), 2.14 (s, 3H, $\mathrm{CH}_{3}-1$ '”), 4.304.36 (m, 4H, $\left.\mathrm{CH}_{2}-2, \mathrm{CH}_{2}-3\right), 4.56$ (s, 2H, $\mathrm{CH}_{2}-7$ ”), 6.95 $\left(\mathrm{dd}, J_{1}=8.4 \mathrm{~Hz}, J_{2}=2.1 \mathrm{~Hz}, 1 \mathrm{H}, \mathrm{H}-4^{\prime}\right), 7.00(\mathrm{~d}, J=8.4 \mathrm{~Hz}$, $1 \mathrm{H}, \mathrm{H}-3$ '), 7.03 (s, 1H, H-6'), 7.09-7.20 (m, 5H, H-2" to H-6”), 7.56 (d, J=8.4 Hz, 1H, H-8), 7.62 (d, $J=2.1 \mathrm{~Hz}, 1 \mathrm{H}$, $\mathrm{H}-5), 7.71\left(\mathrm{dd}, J_{1}=8.4 \mathrm{~Hz}, J_{2}=2.4 \mathrm{~Hz}, 1 \mathrm{H}, \mathrm{H}-7\right)$; EIMS: $m / z 409[\mathrm{M}]^{+}, 345\left[\mathrm{M}-\mathrm{SO}_{2}\right]^{+}, 304\left[\mathrm{C}_{6} \mathrm{H}_{3} \mathrm{C}_{2} \mathrm{H}_{4} \mathrm{O}_{2} \mathrm{SO}_{2} \mathrm{~N}-\right.$ $\left.\mathrm{CH}_{2} \mathrm{C}_{6} \mathrm{H}_{5}\right]^{+}, 199\left[\mathrm{C}_{6} \mathrm{H}_{3} \mathrm{C}_{2} \mathrm{H}_{4} \mathrm{O}_{2} \mathrm{SO}_{2}\right]^{+}, 135\left[\mathrm{C}_{6} \mathrm{H}_{3} \mathrm{C}_{2} \mathrm{H}_{4} \mathrm{O}_{2}\right]^{+}$, $107 \quad\left[\mathrm{C}_{6} \mathrm{H}_{3} \mathrm{O}_{2}\right]^{+}, 105 \quad\left[\mathrm{C}_{6} \mathrm{H}_{3}\left(\mathrm{CH}_{3}\right)_{2}\right]^{+}, 91\left[\mathrm{C}_{7} \mathrm{H}_{7}\right]^{+}, 90$ $\left[\mathrm{C}_{6} \mathrm{H}_{3} \mathrm{CH}_{3}\right]^{+}, 79\left[\mathrm{C}_{4} \mathrm{H}\left(\mathrm{CH}_{3}\right)_{2}\right]^{+}, 75\left[\mathrm{C}_{6} \mathrm{H}_{3}\right]^{+}, 65\left[\mathrm{C}_{5} \mathrm{H}_{5}\right]^{+}, 64$ $\left[\mathrm{C}_{4} \mathrm{HCH}_{3}\right]^{+}$.

\section{$N$-Benzyl- $N$-(2,6-dimethylphenyl)-2,3-dihydrobenzo $[1,4]$ dioxine-6-sulfonamide (6d)}

Creamy white crystalline solid; yield: $72 \%$ (92.3 mg); m.p. $156-158{ }^{\circ} \mathrm{C}$; molecular formula: $\mathrm{C}_{23} \mathrm{H}_{23} \mathrm{NO}_{4} \mathrm{~S}$; molecular weight: $409 \mathrm{~g} / \mathrm{mol}$; HR-MS: [M] ${ }^{+} 409.4991$ (Calcd. for $\mathrm{C}_{23} \mathrm{H}_{23} \mathrm{NO}_{4} \mathrm{~S}$; 409.5187); IR ( $\left.\mathrm{KBr}, \mathrm{cm}^{-1}\right): v_{\max }$ stretching: $3422(\mathrm{~N}-\mathrm{H}), 3013$ (C-H Ar ring), $2927\left(-\mathrm{CH}_{2}-\right), 1643$ (C=C Ar ring), $1325\left(-\mathrm{SO}_{2}-\right), 1126$ (C-O-C of ether); ${ }^{1} \mathrm{H}$ NMR (400 MHz, CD $3 \mathrm{OD}): \delta(\mathrm{ppm}) 2.68$ (s, 6H, $\mathrm{CH}_{3}-1$ '”, $\mathrm{CH}_{3}-2$ "'), 4.23-4.33 (m, 4H, $\left.\mathrm{CH}_{2}-2, \mathrm{CH}_{2}-3\right), 4.61$ (s, $2 \mathrm{H}$, $\mathrm{CH}_{2}-7^{\prime \prime}$ ), 6.14-6.94 (m, 5H, H-2" to H-6"), 6.96 (brd, $J=$ $8.8 \mathrm{~Hz}, 2 \mathrm{H}, \mathrm{H}-3$ ' H-5'), 7.01 (brd, $J=8.8 \mathrm{~Hz}, 1 \mathrm{H}, \mathrm{H}-4$ '), 7.27 (d, $J=8.0 \mathrm{~Hz}, 1 \mathrm{H}, \mathrm{H}-8), 7.32$ (d, $J=2.0 \mathrm{~Hz}, 1 \mathrm{H}, \mathrm{H}-5)$, $7.58\left(\mathrm{dd}, J_{1}=8.4 \mathrm{~Hz}, J_{2}=2.0 \mathrm{~Hz}, 1 \mathrm{H}, \mathrm{H}-7\right)$, EIMS: $m / z 409$ $[\mathrm{M}]^{+}, 345\left[\mathrm{M}-\mathrm{SO}_{2}\right]^{+}, 304\left[\mathrm{C}_{6} \mathrm{H}_{3} \mathrm{C}_{2} \mathrm{H}_{4} \mathrm{O}_{2} \mathrm{SO}_{2} \mathrm{NCH}_{2} \mathrm{C}_{6} \mathrm{H}_{5}\right]^{+}$, $199\left[\mathrm{C}_{6} \mathrm{H}_{3} \mathrm{C}_{2} \mathrm{H}_{4} \mathrm{O}_{2} \mathrm{SO}_{2}\right]^{+}, 135 \quad\left[\mathrm{C}_{6} \mathrm{H}_{3} \mathrm{C}_{2} \mathrm{H}_{4} \mathrm{O}_{2}\right]^{+}, 107$ $\left[\mathrm{C}_{6} \mathrm{H}_{3} \mathrm{O}_{2}\right]^{+}, 105 \quad\left[\mathrm{C}_{6} \mathrm{H}_{3}\left(\mathrm{CH}_{3}\right)_{2}\right]^{+}, 91 \quad\left[\mathrm{C}_{7} \mathrm{H}_{7}\right]^{+}, 90\left[\mathrm{C}_{6} \mathrm{H}_{3}\right.$ $\left.\mathrm{CH}_{3}\right]^{+}, 79\left[\mathrm{C}_{4} \mathrm{H}\left(\mathrm{CH}_{3}\right)_{2}\right]^{+}, 75\left[\mathrm{C}_{6} \mathrm{H}_{3}\right]^{+}, 65\left[\mathrm{C}_{5} \mathrm{H}_{5}\right]^{+}, 64$ $\left[\mathrm{C}_{4} \mathrm{HCH}_{3}\right]^{+}$.

\section{$N$-Benzyl- $N$-(3,4-dimethylphenyl)-2,3-dihydroben- zo[1,4] dioxine-6-sulfonamide (6e) \\ White solid; yield: $90 \%$ (115.4 mg); m.p. $118-120{ }^{\circ} \mathrm{C}$; molecular formula: $\mathrm{C}_{23} \mathrm{H}_{23} \mathrm{NO}_{4} \mathrm{~S}$; molecular weight: $409 \mathrm{~g} /$ mol; HR-MS: $[\mathrm{M}]^{+} 409.4991$ (Calcd. for $\mathrm{C}_{23} \mathrm{H}_{23} \mathrm{NO}_{4} \mathrm{~S}$;}

409.5187); IR $\left(\mathrm{KBr}, \mathrm{cm}^{-1}\right): v_{\max }$ stretching: $3416(\mathrm{~N}-\mathrm{H})$, 3055 (C-H Ar ring), $2943\left(-\mathrm{CH}_{2}-\right), 1622$ (C=C Ar ring), $1322\left(-\mathrm{SO}_{2}\right), 1134$ (C-O-C of ether); ${ }^{1} \mathrm{H}$ NMR (400 $\left.\mathrm{MHz} \mathrm{CDCl}_{3}\right): \delta$ (ppm) 2.10 (s, 3H, $\mathrm{CH}_{3}-2$ "'), 2.14 (s, 3H, $\left.\mathrm{CH}_{3}-1^{\prime \prime}\right)$, 4.28-4.31 (m, $\left.4 \mathrm{H}, \mathrm{CH}_{2}-2, \mathrm{CH}_{2}-3\right), 4.65$ (s, $2 \mathrm{H}$, $\left.\mathrm{CH}_{2}-7^{\prime \prime}\right), 6.66$ (d, J = 7.2 Hz, 1H, H-5'), 6.78 (s, 1H, H-2'), $6.81(\mathrm{~d}, J=7.2 \mathrm{~Hz}, 1 \mathrm{H}, \mathrm{H}-6$ ), $6.88-6.90(\mathrm{~m}, 5 \mathrm{H}, \mathrm{H}-2$ ” to H-6”), 6.92 (d, $J=8.4 \mathrm{~Hz}, 1 \mathrm{H}, \mathrm{H}-8), 7.12$ (dd, $J_{1}=8.4 \mathrm{~Hz}$, $\left.J_{2}=2.0 \mathrm{~Hz}, 1 \mathrm{H}, \mathrm{H}-7\right), 7.21$ (d, $\left.J=2.0 \mathrm{~Hz}, 1 \mathrm{H}, \mathrm{H}-5\right)$; EIMS: $m / z 409[\mathrm{M}]^{+}, 345\left[\mathrm{M}-\mathrm{SO}_{2}\right]^{+}, 304\left[\mathrm{C}_{6} \mathrm{H}_{3} \mathrm{C}_{2} \mathrm{H}_{4} \mathrm{O}_{2} \mathrm{SO}_{2} \mathrm{~N}-\right.$ $\left.\mathrm{CH}_{2} \mathrm{C}_{6} \mathrm{H}_{5}\right]^{+}, 199\left[\mathrm{C}_{6} \mathrm{H}_{3} \mathrm{C}_{2} \mathrm{H}_{4} \mathrm{O}_{2} \mathrm{SO}_{2}\right]^{+}, 135\left[\mathrm{C}_{6} \mathrm{H}_{3} \mathrm{C}_{2} \mathrm{H}_{4} \mathrm{O}_{2}\right]^{+}$, $107\left[\mathrm{C}_{6} \mathrm{H}_{3} \mathrm{O}_{2}\right]^{+}, 105 \quad\left[\mathrm{C}_{6} \mathrm{H}_{3}\left(\mathrm{CH}_{3}\right)_{2}\right]^{+}, 91 \quad\left[\mathrm{C}_{7} \mathrm{H}_{7}\right]^{+}, 90$ $\left[\mathrm{C}_{6} \mathrm{H}_{3} \mathrm{CH}_{3}\right]^{+}, 79\left[\mathrm{C}_{4} \mathrm{H}\left(\mathrm{CH}_{3}\right)_{2}\right]^{+}, 75\left[\mathrm{C}_{6} \mathrm{H}_{3}\right]^{+}, 65\left[\mathrm{C}_{5} \mathrm{H}_{5}\right]^{+}, 64$ $\left[\mathrm{C}_{4} \mathrm{HCH}_{3}\right]^{+}$.

$N$-(2,3-Dimethylphenyl)- $N$-ethyl-2,3-dihydrobenzo[1,4]dioxine-6-sulfonamide (7a)

Yellow sticky solid; yield: 82 \% (89.2 mg); molecular formula: $\mathrm{C}_{18} \mathrm{H}_{21} \mathrm{NO}_{4} \mathrm{~S}$; molecular weight: $347 \mathrm{~g} / \mathrm{mol}$; HRMS: $[\mathrm{M}]^{+} 347.4302$ (Calcd. for $\mathrm{C}_{18} \mathrm{H}_{21} \mathrm{NO}_{4} \mathrm{~S} ; 347.4587$ ); IR $\left(\mathrm{KBr}, \mathrm{cm}^{-1}\right): v_{\max }$ stretching: $3435(\mathrm{~N}-\mathrm{H}), 3032(\mathrm{C}-\mathrm{H}$ Ar ring), $2929\left(-\mathrm{CH}_{2^{-}}\right), 1625\left(\mathrm{C}=\mathrm{C}\right.$ Ar ring), $1320\left(-\mathrm{SO}_{2}\right)$, 1123 (C-O-C of ether); ${ }^{1} \mathrm{H}$ NMR (400 MHz, $\left.\mathrm{CD}_{3} \mathrm{OD}\right): \delta$ (ppm) 0.96 (t, J=7.2 Hz, 3H, $\left.\mathrm{CH}_{3}-2^{\prime \prime}\right), 2.00$ (s, 3H, $\mathrm{CH}_{3}-$ 2"'), 2.06 (s, 3H, $\left.\mathrm{CH}_{3}-1^{\prime \prime}\right), 3.63$ (q, J= 7.2 Hz, $\left.2 \mathrm{H}, \mathrm{CH}_{2}-1^{\prime \prime}\right)$, 4.20-4.29 (m, $\left.4 \mathrm{H}, \mathrm{CH}_{2}-2, \mathrm{CH}_{2}-3\right), 6.81$ (d, J = 7.6 Hz, $1 \mathrm{H}$, H-4'), 6.93 (t, $J=7.6 \mathrm{~Hz}, 1 \mathrm{H}, \mathrm{H}-5$ '), $7.02(\mathrm{~d}, J=7.2 \mathrm{~Hz}, 1 \mathrm{H}$, H-6'), 7.21 (d, $J=8.0 \mathrm{~Hz}, 1 \mathrm{H}, \mathrm{H}-8), 7.63$ (d, $J=2.4 \mathrm{~Hz}, 1 \mathrm{H}$, $\mathrm{H}-5), 7.75$ (dd, $\left.J_{1}=8.0 \mathrm{~Hz}, J_{2}=2.0 \mathrm{~Hz}, 1 \mathrm{H}, \mathrm{H}-7\right)$; EIMS: $m / z 347[\mathrm{M}]^{+}, 283\left[\mathrm{M}-\mathrm{SO}_{2}\right]^{+}, 268\left[\mathrm{C}_{6} \mathrm{H}_{3} \mathrm{C}_{2} \mathrm{H}_{4} \mathrm{O}_{2} \mathrm{NCH}-\right.$ $\left.{ }_{2} \mathrm{C}_{6} \mathrm{H}_{3}\left(\mathrm{CH}_{3}\right)_{2}\right]^{+}, \quad 242 \quad\left[\mathrm{C}_{6} \mathrm{H}_{3} \mathrm{C}_{2} \mathrm{H}_{4} \mathrm{O}_{2} \mathrm{SO}_{2} \mathrm{NC}_{2} \mathrm{H}_{5}\right]^{+}, \quad 240$ $\left[\mathrm{C}_{6} \mathrm{H}_{3} \mathrm{O}_{2} \mathrm{NCH}_{2} \mathrm{C}_{6} \mathrm{H}_{3}\left(\mathrm{CH}_{3}\right)_{2}\right]^{+}, \quad 227 \quad\left[\mathrm{C}_{6} \mathrm{H}_{3} \mathrm{C}_{2} \mathrm{H}_{4} \mathrm{O}_{2} \mathrm{SO}_{2}\right.$ $\left.\mathrm{NCH}_{2}\right]^{+}, 199\left[\mathrm{C}_{6} \mathrm{H}_{3} \mathrm{C}_{2} \mathrm{H}_{4} \mathrm{O}_{2} \mathrm{SO}_{2}\right]^{+}, 135\left[\mathrm{C}_{6} \mathrm{H}_{3} \mathrm{C}_{2} \mathrm{H}_{4} \mathrm{O}_{2}\right]^{+}$, $107\left[\mathrm{C}_{6} \mathrm{H}_{3} \mathrm{O}_{2}\right]^{+}, 105\left[\mathrm{C}_{6} \mathrm{H}_{3}\left(\mathrm{CH}_{3}\right)_{2}\right]^{+}, 90\left[\mathrm{C}_{6} \mathrm{H}_{3} \mathrm{CH}_{3}\right]^{+}, 79$ $\left[\mathrm{C}_{4} \mathrm{H}\left(\mathrm{CH}_{3}\right)_{2}\right]^{+}, 75\left[\mathrm{C}_{6} \mathrm{H}_{3}\right]^{+}, 64\left[\mathrm{C}_{4} \mathrm{HCH}_{3}\right]^{+}$.

\section{$N$-(2,4-Dimethylphenyl)- $N$-ethyl-2,3-dihydroben- zo $[1,4]$ dioxine-6-sulfonamide (7b)}

Greenish brown sticky solid; yield: $73 \%$ (79.4 mg); molecular formula: $\mathrm{C}_{18} \mathrm{H}_{21} \mathrm{NO}_{4} \mathrm{~S}$; molecular weight: $347 \mathrm{~g} /$ mol; HR-MS: $[\mathrm{M}]^{+} 347.4302$ (Calcd. for $\mathrm{C}_{18} \mathrm{H}_{21} \mathrm{NO}_{4} \mathrm{~S}$; 347.4587); IR $\left(\mathrm{KBr}, \mathrm{cm}^{-1}\right): v_{\max }$ stretching: $3430(\mathrm{~N}-\mathrm{H})$, 3044 (C-H Ar ring), $2918\left(-\mathrm{CH}_{2^{-}}\right), 1629$ (C=C Ar ring), $1328\left(-\mathrm{SO}_{2}-\right), 1120$ (C-O-C of ether); ${ }^{1} \mathrm{H}$ NMR (400 MHz, $\mathrm{CD}_{3} \mathrm{OD}$ ): $\delta$ (ppm) 1.00 (t, $J=7.2 \mathrm{~Hz}, 2 \mathrm{H}, \mathrm{CH}_{3}-2$ "), 2.20 (s, $3 \mathrm{H}, \mathrm{CH}_{3}-2$ "'), 2.27 (s, 3H, $\left.\mathrm{CH}_{3}-1^{\prime \prime}\right), 3.77$ (q, J=7.6 Hz, $2 \mathrm{H}$, $\mathrm{CH}_{2}-1$ "), 4.28-4.33 (m, 4H, $\left.\mathrm{CH}_{2}-2, \mathrm{CH}_{2}-3\right), 6.48$ (s, $1 \mathrm{H}$, H-3'), 6.50 (d, $\left.J=7.6 \mathrm{~Hz}, 1 \mathrm{H}, \mathrm{H}-5^{\prime}\right), 6.90$ (d, $J=7.6 \mathrm{~Hz}, 1 \mathrm{H}$, H-6'), 6.97 (d, J = 8.0 Hz, 1H, H-8), 7.10 (d, J=2.4 Hz, $1 \mathrm{H}$, $\mathrm{H}-5$ ), 7.12 (dd, $\left.J_{1}=8.2 \mathrm{~Hz}, J_{2}=2.0 \mathrm{~Hz}, 1 \mathrm{H}, \mathrm{H}-7\right)$; EIMS: $m / z 347[\mathrm{M}]^{+}, 283\left[\mathrm{M}-\mathrm{SO}_{2}\right]^{+}, 268\left[\mathrm{C}_{6} \mathrm{H}_{3} \mathrm{C}_{2} \mathrm{H}_{4} \mathrm{O}_{2} \mathrm{NCH}-\right.$ $\left.{ }_{2} \mathrm{C}_{6} \mathrm{H}_{3}\left(\mathrm{CH}_{3}\right)_{2}\right]^{+}, \quad 242 \quad\left[\mathrm{C}_{6} \mathrm{H}_{3} \mathrm{C}_{2} \mathrm{H}_{4} \mathrm{O}_{2} \mathrm{SO}_{2} \mathrm{NC}_{2} \mathrm{H}_{5}\right]^{+}, \quad 240$ $\left[\mathrm{C}_{6} \mathrm{H}_{3} \mathrm{O}_{2} \mathrm{NCH}_{2} \mathrm{C}_{6} \mathrm{H}_{3}\left(\mathrm{CH}_{3}\right)_{2}\right]^{+}, \quad 227 \quad\left[\mathrm{C}_{6} \mathrm{H}_{3} \mathrm{C}_{2} \mathrm{H}_{4} \mathrm{O}_{2} \mathrm{SO}_{2}\right.$ $\left.\mathrm{NCH}_{2}\right]^{+}, 199\left[\mathrm{C}_{6} \mathrm{H}_{3} \mathrm{C}_{2} \mathrm{H}_{4} \mathrm{O}_{2} \mathrm{SO}_{2}\right]^{+}, 135\left[\mathrm{C}_{6} \mathrm{H}_{3} \mathrm{C}_{2} \mathrm{H}_{4} \mathrm{O}_{2}\right]^{+}$, $107\left[\mathrm{C}_{6} \mathrm{H}_{3} \mathrm{O}_{2}\right]^{+}, 105\left[\mathrm{C}_{6} \mathrm{H}_{3}\left(\mathrm{CH}_{3}\right)_{2}\right]^{+}, 90\left[\mathrm{C}_{6} \mathrm{H}_{3} \mathrm{CH}_{3}\right]^{+}, 79$ $\left[\mathrm{C}_{4} \mathrm{H}\left(\mathrm{CH}_{3}\right)_{2}\right]^{+}, 75\left[\mathrm{C}_{6} \mathrm{H}_{3}\right]^{+}, 64\left[\mathrm{C}_{4} \mathrm{HCH}_{3}\right]^{+}$. 
$\mathrm{N}$-(2,5-Dimethylphenyl)- $\mathrm{N}$-ethyl-2,3-dihydrobenzo $[1,4]$ dioxine-6-sulfonamide $(7 \mathrm{c})$

Light yellow sticky solid; yield: 69\% (75.1 mg); molecular formula: $\mathrm{C}_{18} \mathrm{H}_{21} \mathrm{NO}_{4} \mathrm{~S}$; molecular weight: $347 \mathrm{~g} /$ mol; HR-MS: $[\mathrm{M}]^{+} 347.4302$ (Calcd. for $\mathrm{C}_{18} \mathrm{H}_{21} \mathrm{NO}_{4} \mathrm{~S}$; 347.4587); IR $\left(\mathrm{KBr}, \mathrm{cm}^{-1}\right): v_{\max }$ stretching: $3438(\mathrm{~N}-\mathrm{H})$, 3021 (C-H Ar ring), $2927\left(-\mathrm{CH}_{2}-\right), 1618(\mathrm{C}=\mathrm{C}$ Ar ring), $1326\left(-\mathrm{SO}_{2}-\right), 1129$ (C-O-C of ether); ${ }^{1} \mathrm{H}$ NMR $(500 \mathrm{MHz}$, $\mathrm{CD}_{3} \mathrm{OD}$ ): $\delta$ (ppm) 0.99 (t, $J=7.0 \mathrm{~Hz}, 3 \mathrm{H}, \mathrm{CH}_{3}-2$ "); 2.16 (s, $3 \mathrm{H}, \mathrm{CH}_{3}-2$ "'), 2.27 (s, $3 \mathrm{H}, \mathrm{CH}_{3}-1$ '”), 3.60 (q, $J=7.5 \mathrm{~Hz}, 2 \mathrm{H}$, $\mathrm{CH}_{2}-1$ "), 4.28-4.34 (m, $\left.4 \mathrm{H}, \mathrm{CH}_{2}-2, \mathrm{CH}_{2}-3\right), 6.39(\mathrm{~s}, 1 \mathrm{H}$, H-6'), 6.99 (d, $\left.J=8.5 \mathrm{~Hz}, 1 \mathrm{H}, \mathrm{H}-3^{\prime}\right), 7.04$ (dd, $J=2.0,8.0$ $\mathrm{Hz}, 1 \mathrm{H}, \mathrm{H}-4$ '), 7.09 (d, $J=2.5 \mathrm{~Hz}, 1 \mathrm{H}, \mathrm{H}-5), 7.13$ (dd, $J_{1}=$ $\left.8.5 \mathrm{~Hz}, J_{2}=2.0 \mathrm{~Hz}, 1 \mathrm{H}, \mathrm{H}-7\right), 7.16(\mathrm{~d}, J=7.5 \mathrm{~Hz}, 1 \mathrm{H}, \mathrm{H}-8)$; EIMS: $m / z 347[\mathrm{M}]^{+}, 283\left[\mathrm{M}-\mathrm{SO}_{2}\right]^{+}, 268\left[\mathrm{C}_{6} \mathrm{H}_{3} \mathrm{C}_{2} \mathrm{H}_{4} \mathrm{O}_{2} \mathrm{~N}-\right.$ $\left.\mathrm{CH}_{2} \mathrm{C}_{6} \mathrm{H}_{3}\left(\mathrm{CH}_{3}\right)_{2}\right]^{+}, 242\left[\mathrm{C}_{6} \mathrm{H}_{3} \mathrm{C}_{2} \mathrm{H}_{4} \mathrm{O}_{2} \mathrm{SO}_{2} \mathrm{NC}_{2} \mathrm{H}_{5}\right]^{+}, 240$ $\left[\mathrm{C}_{6} \mathrm{H}_{3} \mathrm{O}_{2} \mathrm{NCH}_{2} \mathrm{C}_{6} \mathrm{H}_{3}\left(\mathrm{CH}_{3}\right)_{2}\right]^{+}, \quad 227 \quad\left[\mathrm{C}_{6} \mathrm{H}_{3} \mathrm{C}_{2} \mathrm{H}_{4} \mathrm{O}_{2} \mathrm{SO}_{2}\right.$ $\left.\mathrm{NCH}_{2}\right]^{+}, 199\left[\mathrm{C}_{6} \mathrm{H}_{3} \mathrm{C}_{2} \mathrm{H}_{4} \mathrm{O}_{2} \mathrm{SO}_{2}\right]^{+}, 135\left[\mathrm{C}_{6} \mathrm{H}_{3} \mathrm{C}_{2} \mathrm{H}_{4} \mathrm{O}_{2}\right]^{+}$, $107\left[\mathrm{C}_{6} \mathrm{H}_{3} \mathrm{O}_{2}\right]^{+}, 105\left[\mathrm{C}_{6} \mathrm{H}_{3}\left(\mathrm{CH}_{3}\right)_{2}\right]^{+}, 90\left[\mathrm{C}_{6} \mathrm{H}_{3} \mathrm{CH}_{3}\right]^{+}, 79$ $\left[\mathrm{C}_{4} \mathrm{H}\left(\mathrm{CH}_{3}\right)_{2}\right]^{+}, 75\left[\mathrm{C}_{6} \mathrm{H}_{3}\right]^{+}, 64\left[\mathrm{C}_{4} \mathrm{HCH}_{3}\right]^{+}$.

\section{$\mathrm{N}$-(2,6-Dimethylphenyl)- $\mathrm{N}$-ethyl-2,3-dihydrobenzo $[1,4]$ dioxine-6-sulfonamide (7d)}

White solid; yield: $78 \%(84.9 \mathrm{mg})$; m.p; $109-111^{\circ} \mathrm{C}$; molecular formula: $\mathrm{C}_{18} \mathrm{H}_{21} \mathrm{NO}_{4} \mathrm{~S}$; molecular weight: $347 \mathrm{~g} /$ mol; HR-MS: $[\mathrm{M}]^{+} 347.4302$ (Calcd. for $\mathrm{C}_{18} \mathrm{H}_{21} \mathrm{NO}_{4} \mathrm{~S}$; 347.4587); IR $\left(\mathrm{KBr}, \mathrm{cm}^{-1}\right): v_{\max }$ stretching: $3445(\mathrm{~N}-\mathrm{H})$, 3017 (C-H Ar ring), $2921\left(-\mathrm{CH}_{2}-\right), 1612(\mathrm{C}=\mathrm{C}$ Ar ring), 1325 (-SO $\left.{ }_{2}\right), 1134$ (C-O-C of ether); ${ }^{1} \mathrm{H}$ NMR $(300 \mathrm{MHz}$, $\mathrm{CD}_{3} \mathrm{OD}$ ): $\delta(\mathrm{ppm}) 1.07$ (t, $J=7.2 \mathrm{~Hz}, 3 \mathrm{H}, \mathrm{CH}_{3}-2$ "), 2.06 (s, $6 \mathrm{H}, \mathrm{CH}_{3}-1$ "', $\left.\mathrm{CH}_{3}-2^{\prime \prime}\right), 3.56\left(\mathrm{q}, J=7.2 \mathrm{~Hz}, 2 \mathrm{H}, \mathrm{CH}_{2}-1\right.$ "), $4.28-4.32\left(\mathrm{~m}, 4 \mathrm{H}, \mathrm{CH}_{2}-2, \mathrm{CH}_{2}-3\right), 6.99(\mathrm{~d}, J=8.4 \mathrm{~Hz}, 2 \mathrm{H}$, H-3', H-5'), 7.02 (d, $\left.J=8.4 \mathrm{~Hz}, 1 \mathrm{H}, \mathrm{H}-4^{\prime}\right), 7.06$ (d, $J=8.4$ $\mathrm{Hz}, 1 \mathrm{H}, \mathrm{H}-8), 7.12$ (d, $J=2.1 \mathrm{~Hz}, 1 \mathrm{H}, \mathrm{H}-5), 7.24$ (dd, $J_{1}=$ $\left.8.4 \mathrm{~Hz}, J_{2}=2.1 \mathrm{~Hz}, 1 \mathrm{H}, \mathrm{H}-7\right)$; EIMS: $m / z 347[\mathrm{M}]^{+}, 283$ $\left[\mathrm{M}-\mathrm{SO}_{2}\right]^{+}, 268 \quad\left[\mathrm{C}_{6} \mathrm{H}_{3} \mathrm{C}_{2} \mathrm{H}_{4} \mathrm{O}_{2} \mathrm{NCH}_{2} \mathrm{C}_{6} \mathrm{H}_{3}\left(\mathrm{CH}_{3}\right)_{2}\right]^{+}, 242$ $\left[\mathrm{C}_{6} \mathrm{H}_{3} \mathrm{C}_{2} \mathrm{H}_{4} \mathrm{O}_{2} \mathrm{SO}_{2} \mathrm{NC}_{2} \mathrm{H}_{5}\right]^{+}, \quad 240 \quad\left[\mathrm{C}_{6} \mathrm{H}_{3} \mathrm{O}_{2} \mathrm{NCH}_{2} \mathrm{C}_{6} \mathrm{H}_{3}\right.$ $\left.\left(\mathrm{CH}_{3}\right)_{2}\right]^{+}, 227 \quad\left[\mathrm{C}_{6} \mathrm{H}_{3} \mathrm{C}_{2} \mathrm{H}_{4} \mathrm{O}_{2} \mathrm{SO}_{2} \mathrm{NCH}_{2}\right]^{+}, 199 \quad\left[\mathrm{C}_{6} \mathrm{H}-\right.$ $\left.{ }_{3} \mathrm{C}_{2} \mathrm{H}_{4} \mathrm{O}_{2} \mathrm{SO}_{2}\right]^{+}, 135\left[\mathrm{C}_{6} \mathrm{H}_{3} \mathrm{C}_{2} \mathrm{H}_{4} \mathrm{O}_{2}\right]^{+}, 107\left[\mathrm{C}_{6} \mathrm{H}_{3} \mathrm{O}_{2}\right]^{+}, 105$ $\left[\mathrm{C}_{6} \mathrm{H}_{3}\left(\mathrm{CH}_{3}\right)_{2}\right]^{+}, 90\left[\mathrm{C}_{6} \mathrm{H}_{3} \mathrm{CH}_{3}\right]^{+}, 79\left[\mathrm{C}_{4} \mathrm{H}\left(\mathrm{CH}_{3}\right)_{2}\right]^{+}, 75$ $\left[\mathrm{C}_{6} \mathrm{H}_{3}\right]^{+}, 64\left[\mathrm{C}_{4} \mathrm{HCH}_{3}\right]^{+}$.

\section{$\mathrm{N}$-(3,4-Dimethylphenyl)- $\mathrm{N}$-ethyl-2,3-dihydrobenzo $[1,4]$ dioxine-6-sulfonamide (7e)}

Yellowish brown sticky solid; yield: 86\% (93.6 mg); molecular formula: $\mathrm{C}_{18} \mathrm{H}_{21} \mathrm{NO}_{4} \mathrm{~S}$; molecular weight: $347 \mathrm{~g} /$ mol; HR-MS: $[\mathrm{M}]^{+} 347.4302$ (Calcd. for $\mathrm{C}_{18} \mathrm{H}_{21} \mathrm{NO}_{4} \mathrm{~S}$; 347.4587); IR $\left(\mathrm{KBr}, \mathrm{cm}^{-1}\right): v_{\max }$ stretching: $3432(\mathrm{~N}-\mathrm{H})$, 3017 (C-H Ar ring), $2923\left(-\mathrm{CH}_{2}-\right), 1612$ (C=C Ar ring), $1325\left(-\mathrm{SO}_{2}-\right), 1134$ (C-O-C of ether); ${ }^{1} \mathrm{H} \mathrm{NMR}(400 \mathrm{MHz}$, $\mathrm{CD}_{3} \mathrm{OD}$ ): $\delta$ (ppm) $1.02\left(\mathrm{t}, J=7.2 \mathrm{~Hz}, 3 \mathrm{H}, \mathrm{CH}_{3}-2\right.$ "), 2.19 (s, $3 \mathrm{H}, \mathrm{CH}_{3}-2$ "'), 2.24 (s, $3 \mathrm{H}, \mathrm{CH}_{3}-1$ '"), 3.55 (q, J=7.2 Hz, $2 \mathrm{H}$, $\mathrm{CH}_{2}-1$ "), $4.26-4.36\left(\mathrm{~m}, 4 \mathrm{H}, \mathrm{CH}_{2}-2, \mathrm{CH}_{2}-3\right), 6.62(\mathrm{~d}, J=8.4$ $\left.\mathrm{Hz}, 1 \mathrm{H}, \mathrm{H}-5^{\prime}\right), 6.71\left(\mathrm{dd}, J_{1}=8.0 \mathrm{~Hz}, J_{2}=2.0 \mathrm{~Hz}, 1 \mathrm{H}, \mathrm{H}-6^{\prime}\right.$ ), $6.81\left(\mathrm{~d}, J=2.0 \mathrm{~Hz}, 1 \mathrm{H}, \mathrm{H}-2^{\prime}\right), 6.94(\mathrm{~d}, J=8.4 \mathrm{~Hz}, 1 \mathrm{H}, \mathrm{H}-8)$, $7.01(\mathrm{~d}, J=2.0 \mathrm{~Hz}, 1 \mathrm{H}, \mathrm{H}-5), 7.06\left(\mathrm{dd}, J_{1}=8.4 \mathrm{~Hz}, J_{2}=2.4\right.$
Hz, 1H, H-7); EIMS: $m / z 347[\mathrm{M}]^{+}, 283\left[\mathrm{M}-S O_{2}\right]^{+}, 268$ $\left[\mathrm{C}_{6} \mathrm{H}_{3} \mathrm{C}_{2} \mathrm{H}_{4} \mathrm{O}_{2} \mathrm{NCH}_{2} \mathrm{C}_{6} \mathrm{H}_{3}\left(\mathrm{CH}_{3}\right)_{2}\right]^{+}, \quad 242 \quad\left[\mathrm{C}_{6} \mathrm{H}_{3} \mathrm{C}_{2} \mathrm{H}_{4} \mathrm{O}-\right.$ $\left.{ }_{2} \mathrm{SO}_{2} \mathrm{NC}_{2} \mathrm{H}_{5}\right]^{+}, 240 \quad\left[\mathrm{C}_{6} \mathrm{H}_{3} \mathrm{O}_{2} \mathrm{NCH}_{2} \mathrm{C}_{6} \mathrm{H}_{3}\left(\mathrm{CH}_{3}\right)_{2}\right]^{+}, 227$ $\left[\mathrm{C}_{6} \mathrm{H}_{3} \mathrm{C}_{2} \mathrm{H}_{4} \mathrm{O}_{2} \mathrm{SO}_{2} \mathrm{NCH}_{2}\right]^{+}, 199\left[\mathrm{C}_{6} \mathrm{H}_{3} \mathrm{C}_{2} \mathrm{H}_{4} \mathrm{O}_{2} \mathrm{SO}_{2}\right]^{+}, 135$ $\left[\mathrm{C}_{6} \mathrm{H}_{3} \mathrm{C}_{2} \mathrm{H}_{4} \mathrm{O}_{2}\right]^{+}, 107\left[\mathrm{C}_{6} \mathrm{H}_{3} \mathrm{O}_{2}\right]^{+}, 105\left[\mathrm{C}_{6} \mathrm{H}_{3}\left(\mathrm{CH}_{3}\right)_{2}\right]^{+}, 90$ $\left[\mathrm{C}_{6} \mathrm{H}_{3} \mathrm{CH}_{3}\right]^{+}, 79\left[\mathrm{C}_{4} \mathrm{H}\left(\mathrm{CH}_{3}\right)_{2}\right]^{+}, 75\left[\mathrm{C}_{6} \mathrm{H}_{3}\right]^{+}, 64\left[\mathrm{C}_{4} \mathrm{HCH}_{3}\right]^{+}$.

\section{3. Enzyme Inhibition Studies}

\section{3. 1. Cholinesterase Assay}

The BChE and AChE inhibition activities were assayed in concurrence with the reported method after making minor changes. ${ }^{33}$ Overall total volume of $100 \mu \mathrm{L}$ was pertained to reaction mixture; made by mixing $60 \mu \mathrm{L}$ of $\mathrm{Na}_{2} \mathrm{HPO}_{4}$ buffer ( $\mathrm{pH}$ 7.7), $10 \mu \mathrm{L}$ of each test sample and the enzyme. The sample and buffer strength was kept at $0.5 \mathrm{mM}$ per well. BChE was added 0.5 unit per well and a quantity of 0.005 units was made constant for AChE in each well. After mixing the contents, the reading was recorded at $405 \mathrm{~nm}$. Before this, incubation of $10 \mathrm{~min}$ at $37^{\circ} \mathrm{C}$ was ensured. On adding $10 \mu \mathrm{L}$ of both substrate $(0.5 \mathrm{mM}$ per well $)$ and DTNB (0.5 $\mathrm{mM}$ per well) the reaction was allowed to start. The substrates for $\mathrm{BChE}$ and $\mathrm{AChE}$ were butyrylthiocholine chloride and acetylthiocholine iodide, respectively. Again the incubation was done for $15 \mathrm{~min}$ at $37^{\circ} \mathrm{C}$. Later on, the absorbance was measured at $405 \mathrm{~nm}$. The instrument used was 96-well plate reader Synergy HT, Biotek, USA. $0.5 \mathrm{mM}$ per well of Eserine was exploited as the positive control. The experiments were carried out in triplicate. The $\%$ inhibition was calculated as:

$$
\text { Inhibition }(\%)=\frac{\text { Control }- \text { Test }}{\text { Control }} \times 100
$$

Here, total enzyme activity without inhibitor is described as control, whereas test corresponds to its activity in the presence of our synthesized molecules. EZ-Fit Enzyme Kinetics software was employed to determine $\mathrm{IC}_{50}$ values. The software was provided by Perrella Scientific Inc. Amherst, USA.

\section{3. 2. Lipoxygenase Assay}

For lipoxygenase assay the total volume of the mixture was maintained at $200 \mu \mathrm{L}$. It contained $150 \mu \mathrm{L}$ of 100 $\mathrm{mM} \mathrm{Na}{ }_{3} \mathrm{PO}_{4}$ buffer having $\mathrm{pH} 8.0,10 \mu \mathrm{L}$ of $0.5 \mathrm{mM}$ per well of the test compound and $15 \mu \mathrm{L}$ of the enzyme. The lipoxygenase was added in 600 units in each well. After mixing and pre-incubation $\left(10 \mathrm{~min} ; 25^{\circ} \mathrm{C}\right)$ the contents were pre-read at $234 \mathrm{~nm}$. On adding $25 \mu \mathrm{L}$ of substrate solution the reaction was initiated. The absorbance was measured at $234 \mathrm{~nm}$ using 96-well plate reader Synergy HT, Biotek, USA. Baicalein was used as the positive control having $0.5 \mathrm{mM}$ per well in the assay. The $\%$ inhibition and rest of calculation was executed by the same method as described above. ${ }^{34-36}$ 


\section{3. 3. Statistical Analysis}

All experimental measurements were recorded three folds. The statistical analysis was achieved by Microsoft Excel 2010.

\section{4. Antimicrobial Activity}

\section{4. 1. Microbial Strains}

A set of microorganisms were used to conduct antimicrobial activity. All the synthesized compounds were tested against fungal, Gram negative and Gram positive bacterial strains. In this study Bacillus subtilis (B. subtilis) JS 2004 and Staphylococcus aureus (S. aureus) API Staph TAC 6736152 were used as Gram positive bacteria, whereas Pasteurella multocida (P. multocida) and Escherichia coli (E. coli) ATCC 25922 were among Gram negative bacteria. The four pathogenic fungi: Microsporum canis (M. canis), Candida albicans (C. albican), Aspergillus flavus (A. flavus) and Fusarium solani (F. solani) were also the constituents of the assay. All the pure strains were provided by CMS department of UAF, Faisalabad. The Department of microbiology checked their purity and confirmed their identification. In nutrient agar (NA, Oxoid) bacterial strains were cultured overnight at $37^{\circ} \mathrm{C}$. For fungal strains Potato Dextrose Agar (PDA, Oxoid) was chosen and subjected to culture at $28{ }^{\circ} \mathrm{C}$ overnight. ${ }^{37}$

\section{4. 2. Disc Diffusion Method}

Disc diffusion method was used to determine antimicrobial activity of synthesized compounds. Suspension of tested microorganisms $(100 \mu \mathrm{L})$ comprised $10^{7}$ colony-forming units (CFU)/mL of bacterial cells. They were expanded on NA medium. The suspension with $10^{6}$ spores/ $\mathrm{mL}$ of fungi were expended on PDA medium. The solution of compound was applied to saturate filter discs. Sample free discs were used for negative control. For the comparison of sensitivity of strain/isolate in the analyzed microbial species, positive reference used for fungi and bacteria were Flumequine (30 $\mu \mathrm{g} / \mathrm{disk})$ (Oxoid, UK) and Amoxycillin (30 $\mu \mathrm{g} / \mathrm{dish}$ ) (Oxoid, UK), respectively. After keeping it at $4{ }^{\circ} \mathrm{C}$ for 2 hours, plates were incubated for 24 hours at 28 ${ }^{\circ} \mathrm{C}$ for fungal strains and for 18 hours at $37^{\circ} \mathrm{C}$ for bacteria. Antimicrobial activity was assessed by calculating the diameter ( $\mathrm{mm}$ of growth) of inhibition zones using zone reader. Later on it was compared with the controls. ${ }^{37}$

\section{4. 3. Hemolytic Activity}

To study the hemolytic activity of the compounds 3 $\mathrm{mL}$ of fresh blood of heparinized human was collected. After consent the bovine from volunteers of the Department of Clinical Medicine and Surgery, University of Agriculture, Faisalabad, Pakistan was bleeded. Centrifugation of blood was done at $1000 \times g$ for $5 \mathrm{~min}$. Plasma was discarded. $5 \mathrm{~mL}$ of chilled $\left(4^{\circ} \mathrm{C}\right)$ sterile isotonic Phosphate Buff- ered Saline (PBS) with pH 7.4 was used to wash the cells. This task was performed for three times. For each assay erythrocytes were maintained $10^{8}$ cells per mL. $100 \mu \mathrm{L}$ of each compound was taken and mixed with $10^{8}$ cells $/ \mathrm{mL}$ of human separately. The incubation of samples was done at $37^{\circ} \mathrm{C}$ for $35 \mathrm{~min}$. After incubation these samples were settled for $10 \mathrm{~min}$ and later on kept on agitation. The samples were placed on ice for $5 \mathrm{~min}$ immediately after incubation then centrifuged at $1000 \times g$ for $5 \mathrm{~min}$. From each tube 100 $\mu \mathrm{L}$ of supernatant was taken and then diluted with chilled $\left(4^{\circ} \mathrm{C}\right)$ PBS 10 times. As the positive control, Triton X-100 $(0.1 \% \mathrm{v} / \mathrm{v})$ was used; while phosphate buffer saline (PBS) acted as the negative control. The $\mu$ Quant's life science instrument licensed by Biotek, USA was used to record the absorbance. The absorbance was taken at $576 \mathrm{~nm}$. The \% RBCs lysis for each sample was measured. ${ }^{38,39}$

\section{5. Molecular Docking}

The structures of all the synthesized inhibitors were constructed using MOE-Builder tool. The default parameters of MOE-Dock program were used for the molecular docking of the ligands. Ligands were allowed to be flexible in order to find the accurate conformations of the ligands and to obtain minimum energy structures. At the end of docking, the best conformations of the ligands were analyzed for their binding interactions. ${ }^{40}$

\section{Results and Discussion}

\section{1. Chemistry}

We report herein the synthesis of a series of heterocyclic compounds containing 1,4-benzodioxane nucleus. The precursor molecules $N$-aryl-2,3-dihydrobenzo[1,4] dioxine-6-sulfonamide 3a-e, were prepared by condensing 1,4-benzodioxane-6-sulfonyl chloride (1) and aryl amines $2 \mathbf{a}-\mathbf{e}$ in basic aqueous medium. Two series of $\mathrm{N}$-substituted derivatives $(\mathbf{6 a}-\mathbf{e}$ and $7 \mathbf{a}-\mathbf{e})$ were formed by the reactions of $3 \mathbf{a}-\mathbf{e}$ with two different electrophiles. The substitution reactions yielded $N$-benzyl $(\mathbf{6 a}-\mathbf{e})$ or $N$-ethyl (7a-e) derivatives of $\mathrm{N}$-aryl-2,3-dihydrobenzo[1,4]dioxine-6-sulfonamides as represented in Scheme 1. The derivatives $6 \mathbf{a}-\mathbf{e}$ and $7 \mathbf{a}-\mathbf{e}$ were obtained in DMF as the solvent and with $\mathrm{LiH}$ as the base and activator. The reaction products were obtained within 30 to $70 \mathrm{~min}$ of stirring at room temperature. By adding cold distilled water along with vigorous shaking of the reaction mixtures, the products were precipitated; isolation through filtration yielded pure solid targets. On the other hand, some sticky and greasy compounds were recovered through solvent extraction method using chloroform as the extracting solvent. Here the description of the parent compound $\mathbf{3 a}$ is given as an example for elaborating the spectral data. $3 \mathbf{a}$ was synthesized as a white powder with good yield (80\%) and m.p. was recorded as $102-104{ }^{\circ} \mathrm{C}$. High Resolution Mass Spectrome- 
try (HR-MS) showed $\mathrm{M}^{\cdot+}$ (molecular ion peak) at $\mathrm{m} / \mathrm{z}$ 319.3772. Therefore, molecular formula of the compound was established as $\mathrm{C}_{16} \mathrm{H}_{17} \mathrm{NO}_{4} \mathrm{~S}$. The total number of pro- tons was confirmed from ${ }^{1} \mathrm{H}$ NMR spectrum. The IR spectrum of 3a confirmed the presence of different functionalities. Like the absorption bands were observed at 3419

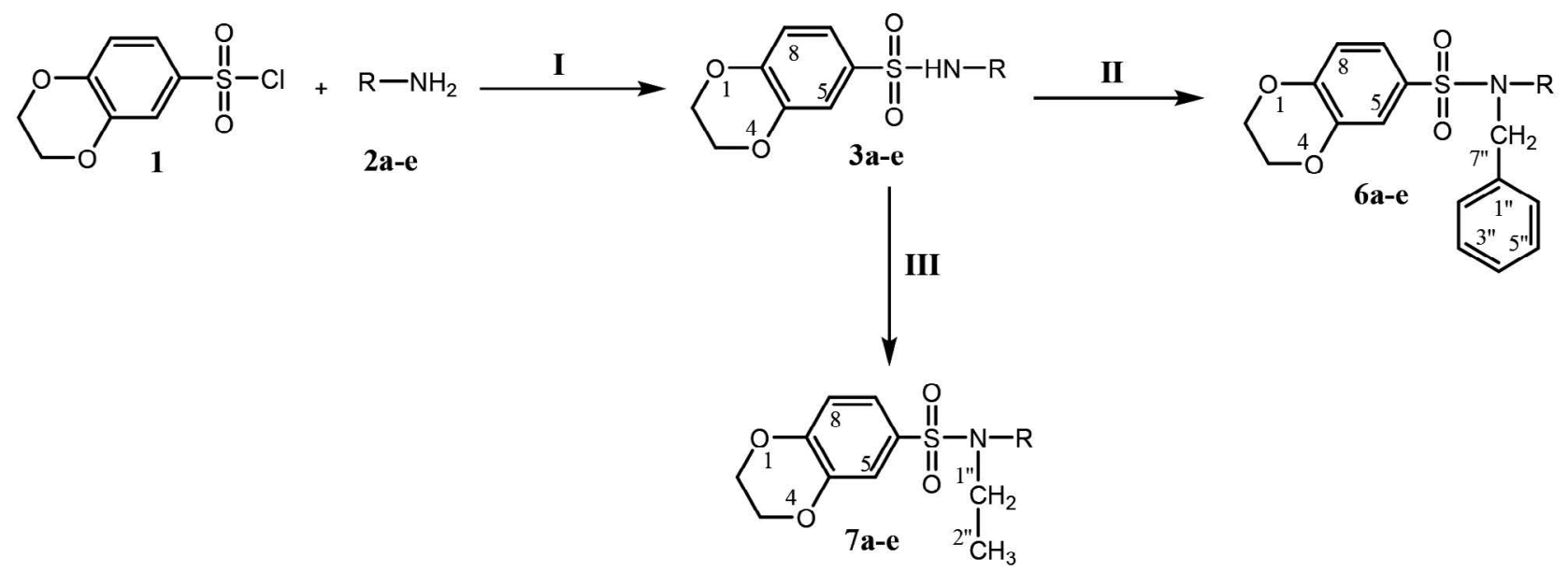

Reagents and conditions: (I) $\mathrm{Na}_{2} \mathrm{CO}_{3}$ (aq), pH 9-10, stir, 3-4h, rt, (II) $\mathrm{C}_{6} \mathrm{H}_{5} \mathrm{CH}_{2} \mathrm{Cl}$ (4), DMF, LiH, stir, 4-5 h, rt (III) $\mathrm{CH}_{3} \mathrm{CH}_{2} \mathrm{I}$ (5), $\mathrm{DMF}$, LiH, stir, $4-5 \mathrm{~h}, \mathrm{rt}$<smiles>Cc1cccc(NS(=O)(=O)c2ccc3c(c2)OCCO3)c1C</smiles>

3a<smiles>[CH2+]c1ccc(NS(=O)(=O)c2ccc3c(c2)OCCO3)c([123I])c1</smiles>

3b<smiles></smiles>

$3 c$<smiles>[CH]c1cccc(C)c1NS(=O)(=O)c1ccc2c(c1)OCCO2</smiles>

3d

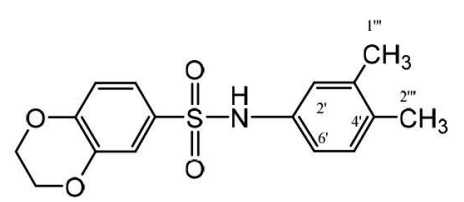

3e
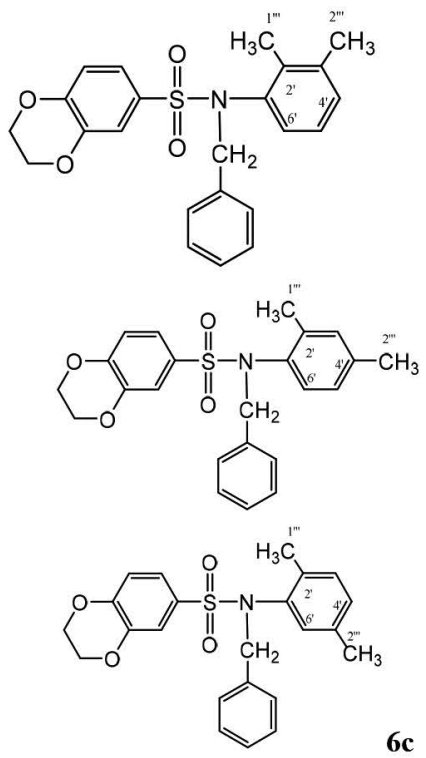

6c

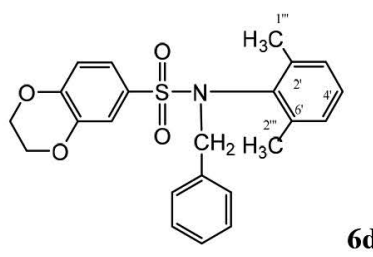

6d

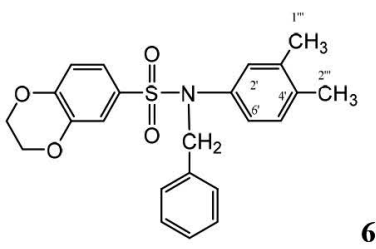

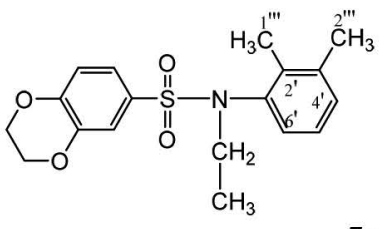

$6 a$<smiles>[CH2-]c1cc(C)ccc1N(CC)S(=O)(=O)c1ccc2c(c1)OCCO2</smiles>

6b<smiles>[CH2-]c1ccc([CH2-])c(N(CC)S(=O)(=O)c2ccc3c(c2)OCCO3)c1</smiles><smiles>[CH2-]c1cccc(C)c1N(CC)S(=O)(=O)c1ccc2c(c1)OCCO2</smiles>

7d<smiles>[CH2+]c1ccc(N(CC)S(=O)(=O)c2ccc3c(c2)OCCO3)cc1[12F]</smiles>

Scheme 1. Synthetic scheme and sulfonamide compounds bearing benzodioxane nucleus. 
$\mathrm{cm}^{-1}$ for N-H stretching of sulfamoyl group and at 3026 $\mathrm{cm}^{-1}$ for aromatic C-H stretching. A peak at $1613 \mathrm{~cm}^{-1} \mathrm{de}-$ picted the presence of $\mathrm{C}=\mathrm{C}$ stretching of $\mathrm{Arl}$ ring. A stretching band at $1325 \mathrm{~cm}^{-1}$ confirmed the $\mathrm{SO}_{2}$ stretching of sulfonyl group in the molecule. A characteristic band at $1125 \mathrm{~cm}^{-1}$ was assigned to $\mathrm{C}-\mathrm{O}-\mathrm{C}$ stretching of ether, respectively. The EI-MS gave characteristic peaks at $\mathrm{m} / \mathrm{z}$ 199 and 90. These were attributed to the formation of
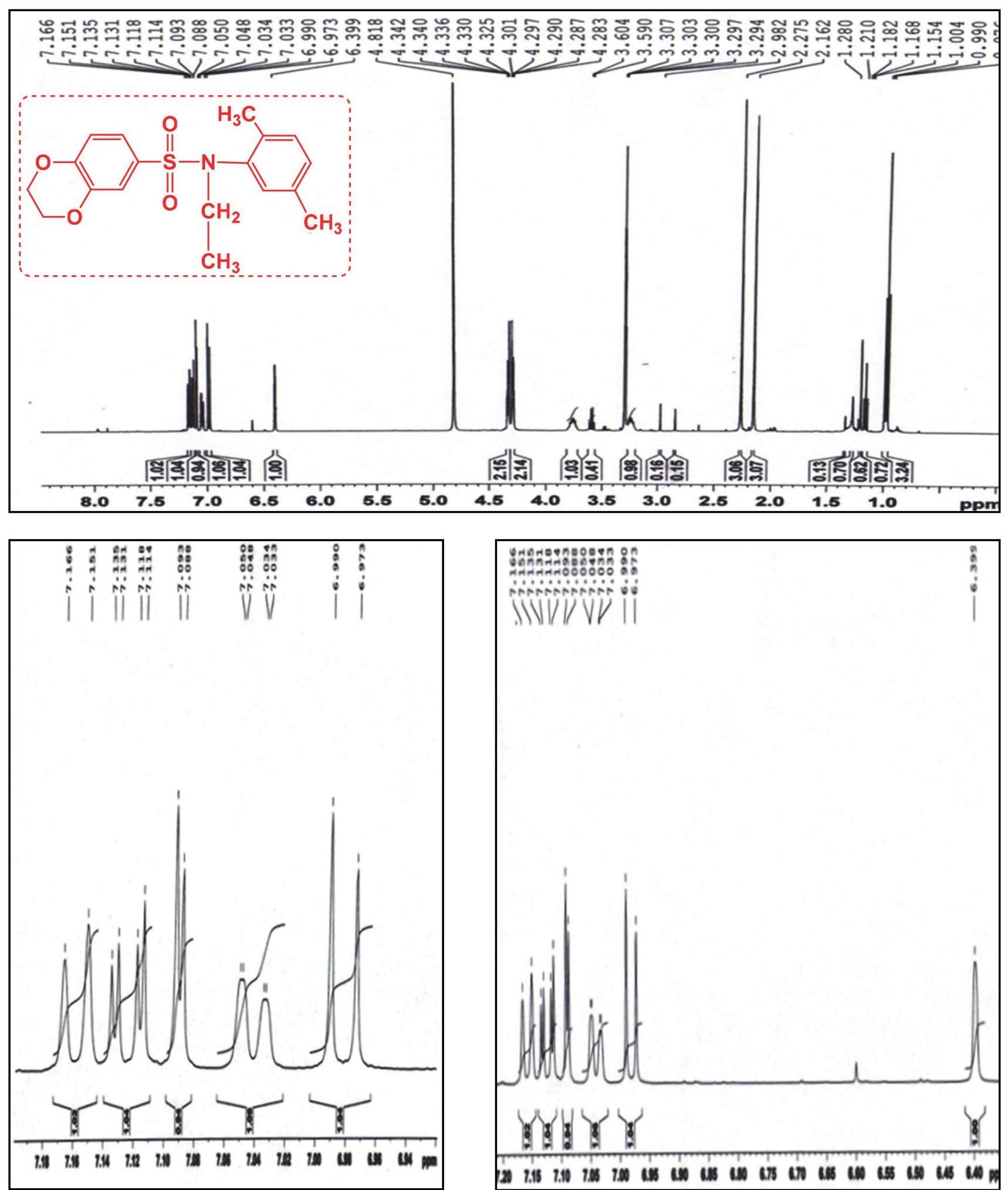

Figure 1a. ${ }^{1} \mathrm{H}$ NMR spectrum of $N$-(2,5-dimethylphenyl)- $N$-ethyl-2,3-dihydrobenzo[1,4] dioxine-6-sulfonamide 7c (aromatic region) 

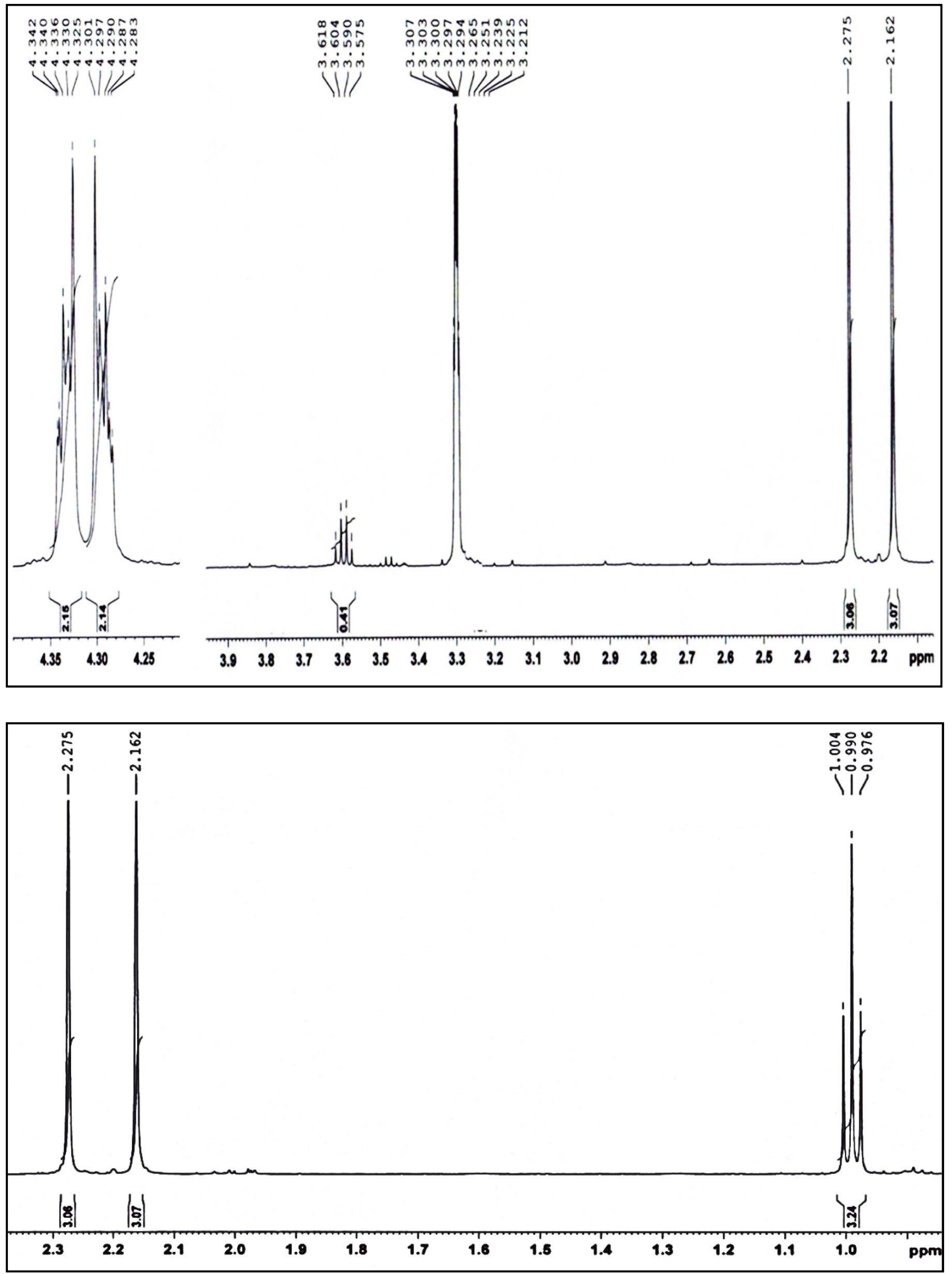

Figure 1b. ${ }^{1} \mathrm{H}$ NMR spectrum of $N$-(2,5-dimethylphenyl)- $N$-ethyl-2,3-dihydrobenzo[1,4] dioxine-6-sulfonamide 7c (aliphatic region) 
$\mathrm{C}_{6} \mathrm{H}_{3} \mathrm{C}_{2} \mathrm{H}_{4} \mathrm{O}_{2} \mathrm{SO}_{2}{ }^{+}$and $\mathrm{C}_{6} \mathrm{H}_{3} \mathrm{CH}_{3}{ }^{+}$cations, respectively. In the aromatic region of the ${ }^{1} \mathrm{H}$ NMR spectrum signals appeared at $\delta 7.25$ as doublet (small coupling constant) confirming $\mathrm{H}-5$, doublet of doublet at chemical shift of 7.18 showed presence of $\mathrm{H}-7$ and another doublet at $\delta 6.95$ (large coupling constant) indicated $\mathrm{H}-8$ of phenyl ring attached to the sulfonyl group. Whereas three aromatic signals at $\delta 6.80(\mathrm{brd}), 6.78(\mathrm{t})$ and $6.73(\mathrm{brd})$ were assigned to the benzene ring of 2,3-dimethylphenyl group. In the shielded, upfield and aliphatic region of the spectrum three distinct signals appeared. The multiplet ranging from 4.24 $4.27\left(\mathrm{CH}_{2}-2, \mathrm{CH}_{2}-3\right)$, singlet at $2.27\left(\mathrm{CH}_{3}-1\right.$ ") and relatively higher upfield singlet at $1.99\left(\mathrm{CH}_{3}-2\right)$ indicated the presence of 1,4-dioxane nucleus and two methyl groups attached to the second and third position of aniline in the molecule. The structure of $\mathbf{3 a}$ was established as (2,3-di-

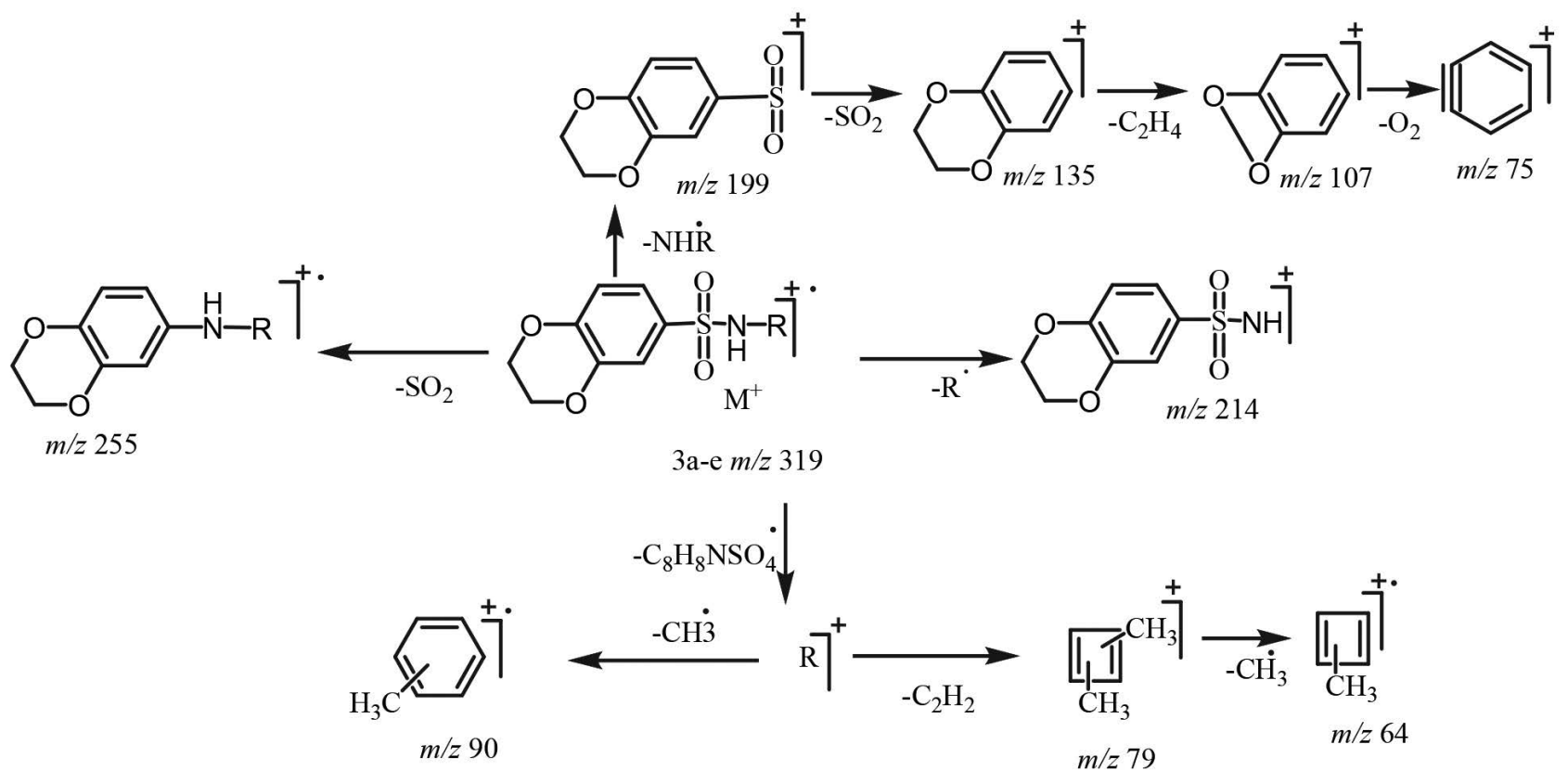

Figure 2. Mass fragmentation pattern of $N$-aryl-2,3-dihydrobenzo[1,4]dioxine-6-sulfonamides 3a-e

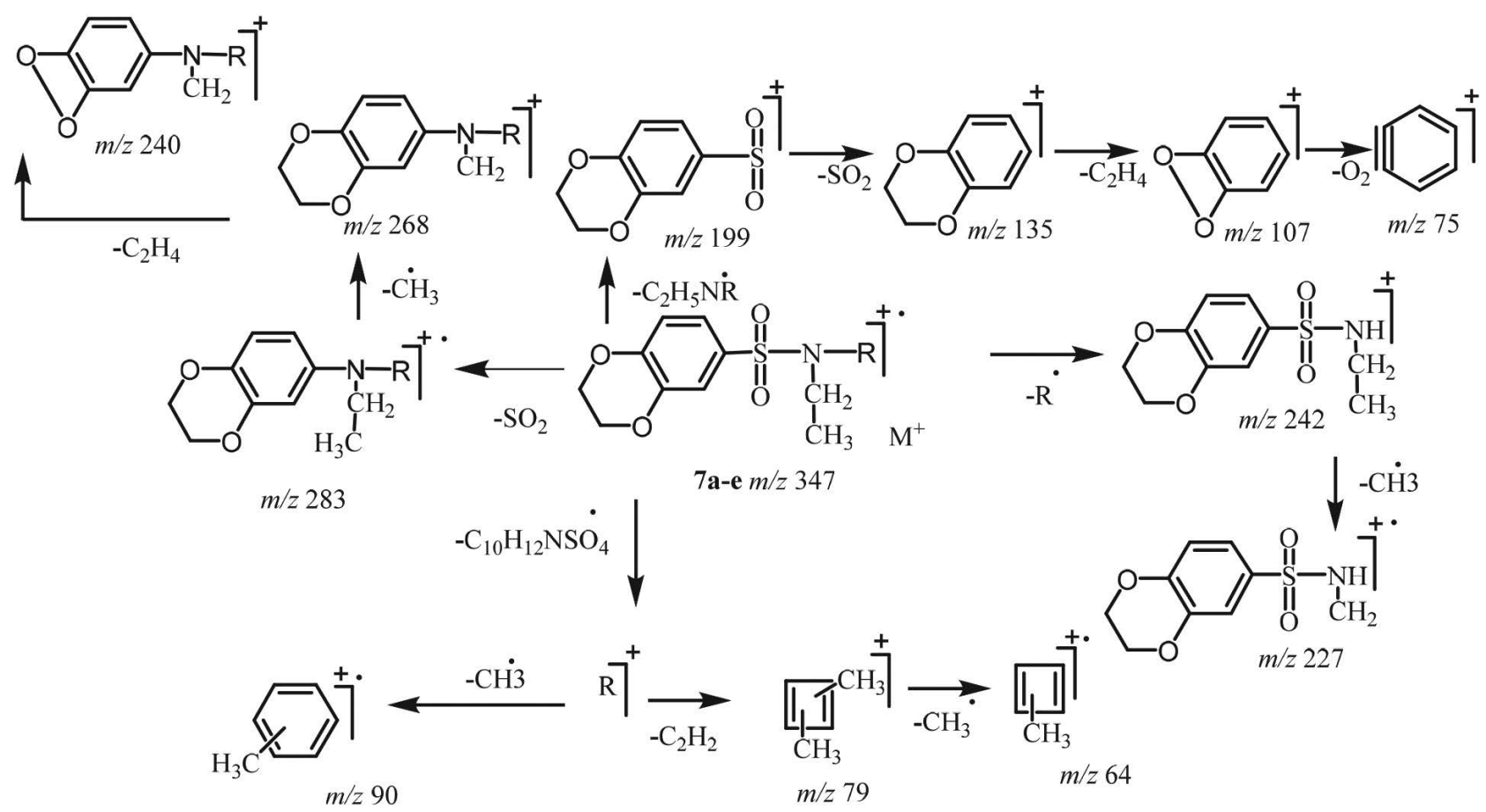

Figure 3. Mass fragmentation pattern of $N$-ethyl- $N$-(dimethylphenyl)-2,3-dihydrobenzo[1,4] dioxine-6-sulfonamide 7a-e 
methylphenyl)-2,3-dihydrobenzo[1,4] dioxine-6-sulfonamide on these collective confirmations. The structures of other derivatives were also ascertained on the similar pattern. The ${ }^{1} \mathrm{H}$ NMR spectrum of molecule $7 \mathrm{c}$ is shown in Figure 1. The mass fragmentation pattern of parent sulfonamides $3 \mathbf{a}-\mathbf{e}$ and their $\mathrm{N}$-ethyl derivatives $7 \mathbf{a}-\mathbf{e}$ are provided in Figures 2 and 3.

\section{2. Enzyme Inhibition}

The screening of all the synthesized compounds against butyrylcholinesterase enzyme revealed that only three compounds showed better activity; $\mathrm{N}$-(2,3-dimethylphenyl)-2,3-dihydrobenzo[1,4]dioxine-6-sulfonamide (3a), N-benzyl-(2,5-dimethylphenyl)-2,3-dihydro- benzo[1,4] dioxine-6-sulfonamide (6c) and $N$-ethyl-(2,4-dimethylphenyl)-2,3 -dihydro- benzo[1,4]dioxine-6-sulfonamide (7b) having $\mathrm{IC}_{50}$ values of $374.11 \pm 0.01,387.51 \pm 0.48$ and $353.13 \pm 0.86 \mu \mathrm{mol} / \mathrm{L}$ respectively, relative to eserine, a reference standard with $\mathrm{IC}_{50}$ value of $0.85 \pm 0.0001$ $\mu \mathrm{mol} / \mathrm{L}$ (Table 1 ). The activity of these compounds was most probably due to the presence of methyl groups at different positions of phenyl ring in $\mathbf{3 a}$, benzyl group in $\mathbf{6 c}$ along with alkyl groups and an additional ethyl group for $\mathbf{7 b}$ attached to the nitrogen of sulfonamide. The screening against acetylcholinesterase enzyme of all the synthesized compounds showed that only four compounds were moderately active against it; i.e. $N$-(3,4dimethylphenyl)-2,3-dihydrobenzo[1,4]dioxine-6-sulfonamide (3e), N-benzyl-N-(2,4-dimethylphenyl)-2,3-dihydrobenzo[1,4] dioxine-6-sulfonamide (6b), $\mathrm{N}$-ethyl- $\mathrm{N}$-(2,4-dimethylphenyl)-2,3-dihy-drobenzo[1,4] dioxine-6-sulfonamide (7b) and $\mathrm{N}$-ethyl- $\mathrm{N}$-(2,6-dimethylphenyl) -2,3-dihydrobenzo[1,4] dioxine-6-sulfonamide (7d) having $\mathrm{IC}_{50}$ values ranging from $178.51 \pm 0.14$ to $364.27 \pm 0.54 \mu \mathrm{mol} / \mathrm{L}$. The relative reference standard was eserine, with $\mathrm{IC}_{50}$ value of $0.04 \pm 0.0001 \mu \mathrm{mol} / \mathrm{L}$. The $\%$ inhibition associated with these compounds arrayed from $59.91 \pm 0.96$ to $76.56 \pm 0.19 \mu \mathrm{mol} / \mathrm{L}$ respectively. The proficient activity was observed for $\mathbf{7 b}$ and $\mathbf{7 d}$; this was most likely due to the occurrence of $\mathrm{N}$-ethyl group in these compounds in comparison to the other series members. Against lipoxygenase enzyme, all the synthesized compounds showed beneficially good activity but the most active were $\mathrm{N}$-(2,6-dimethylphenyl)-2,3-dihydrobenzo [1,4] dioxine6-sulfonamide (3d), $\mathrm{N}$-(2,4-dimethylphenyl)-2,3-dihydrobenzo [1,4] dioxine-6-sulfonamide (3b), $N$-benzyl- $N$-(2,6-dimethylphenyl)-2,3-dihydrobenzo $\quad[1,4]$ dioxine-6-sulfonamide (6d) and $N$-(3,4-dimethylphenyl)-2,3-dihydrobenzo[1,4] dioxine-6-sulfonamide (3e) having $\mathrm{IC}_{50}$ values of $34.21 \pm 0.12,64.21 \pm$ $0.05,84.61 \pm 0.11$ and $87.61 \pm 0.14 \mu \mathrm{mol} / \mathrm{L}$ respectively, relative to baicalein, a reference standard with $\mathrm{IC}_{50}$

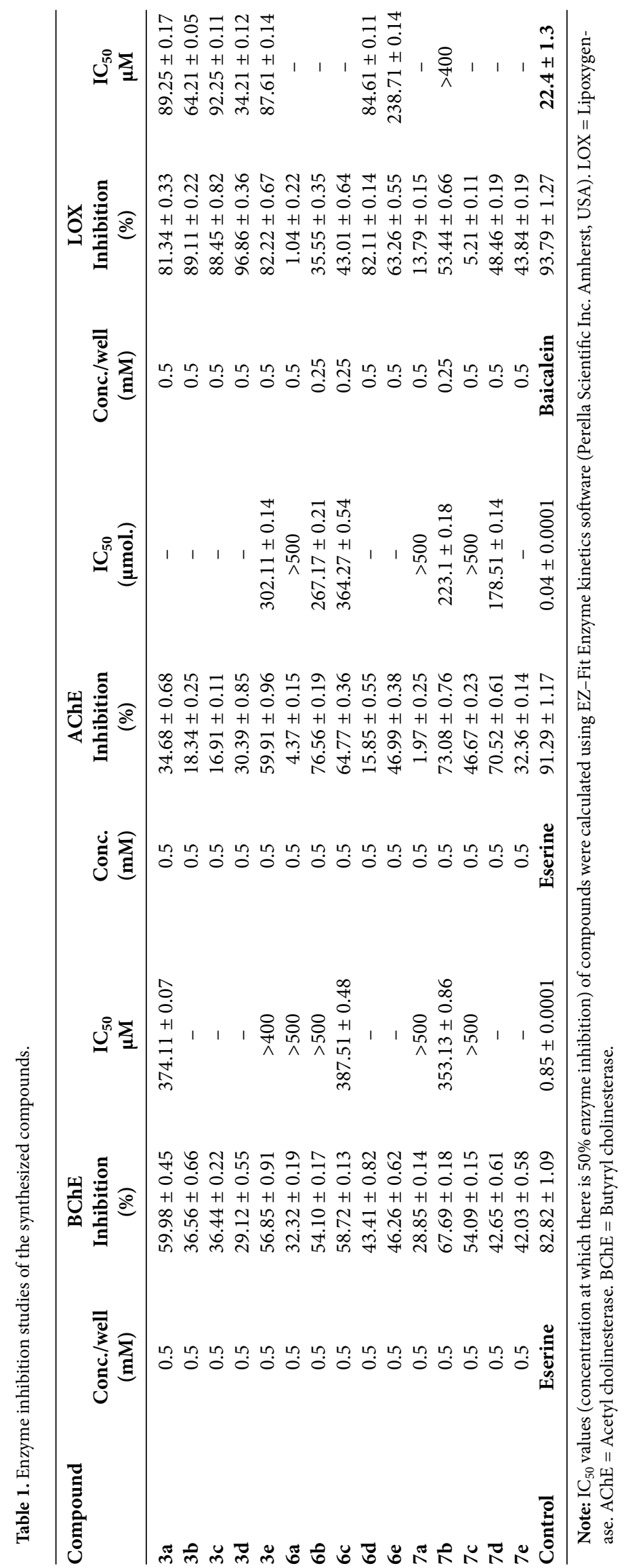


value of $22.4 \pm 1.3 \mu \mathrm{mol} / \mathrm{L}$. The proficient activity of first and second compounds was most probably due to the occurrence of two alkyl groups, one at the second position and the other one at the sixth and fourth positions of aniline ring, respectively. In $3 \mathbf{e}$ these two alkyl groups were situated at the third and fourth positions and resulted in less inhibition in comparison to $\mathbf{3 d}$ and $\mathbf{3 b}$. For 6d the credibly was due to the presence of two alkyl groups at the second and sixth position of aniline ring along with benzyl group attached to the nitrogen of sulfonamide. From the activity of molecules against LOX it might be concluded that free nitrogen of sulfamoyl group could be more effective in blocking the active site of enzyme; instead when we substitute it with ethyl or benzyl groups. All the parent compounds $\mathbf{3 a}-\mathbf{e}$ can be further utilized for the synthesis of new derivatives with other different electrophiles to enhance their biological, antimicrobial and other activities.

\section{3. Antimicrobial Activity}

The in vitro antimicrobial properties of the parent compounds 3 and their derivatives were tested. Against the selected panel of both bacterial and fungal species parent compounds $\mathbf{3 a}, \mathbf{3 b}, \mathbf{3} \mathbf{c}$ and $3 \mathbf{e}$ exhibited moderate antimicrobial activity; and $3 \mathbf{c}$ showed only antibacterial activity as is evident from Table 2. Regarding these parent sulfonamides $\mathbf{3}$, the compound $\mathbf{3 e}$ showed relatively higher activity but lower than that of the standard compound. Among the derivatives of $\mathbf{6 a}-\mathbf{e}$ series 6a and $\mathbf{6 c}$ have shown both the antibacterial and antifungal activities; and $\mathbf{6 a}$ demonstrated higher activities in contrast to the other series members. $7 \mathbf{a}, 7 \mathbf{b}$ and $7 \mathbf{c}$ are the members of $7 \mathbf{a}-\mathbf{e}$ series which were active against both bacterial and fungal strains; among these $\mathbf{7 b}$ exhibited relatively better results against both microbes. The remaining compounds possess very low or no activity against the assessed microorganisms. The highest hemolytic activity was shown by $\mathbf{3 b}(92 \%)$ but lower than the positive control (Triton-X-100). The lowest hemolytic activity was shown by $\mathbf{7 b}$ and $7 \mathrm{c}(2.1 \%$ and $0.7 \%$, respectively) but higher than the negative controls (PBS). Overall it can be concluded here that $\mathbf{7 b}$ and $\mathbf{7 c}$ were the better members overall from all these compounds and ligands; because they have displayed better antimicrobial potential and less hemolytic activity. On the basis of the presented results we may assume that the synthesized sulfonamides may be suitable leads for further improvement to address different targets.

유

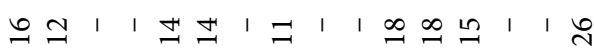

$\exists \smile$

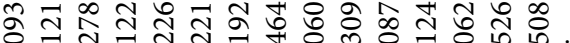
$+1+1+1+1+1+1+1+1+1+1+1+1+1+1+1=0$ 前

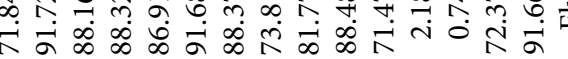

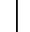




\section{Molecular Docking}

The results obtained from in silico approach were also favoring the fact that the synthesized sulfonamides have shown good interactions with the target site. The interaction analysis has shown that in every compound the sulfonamide group is contributing to the interactions. The interactions of compounds $\mathbf{3 b}$ and $\mathbf{7 d}$ with the active site of lipoxygenase (LOX) and acetylcholinesterase (AChE) are shown in Figures 4 and 5, respectively.

The interaction analysis of compound $\mathbf{7 d}$ against acetylcholinesterase depicted that the residues of the binding pocket interacted with two functionalities of the com-

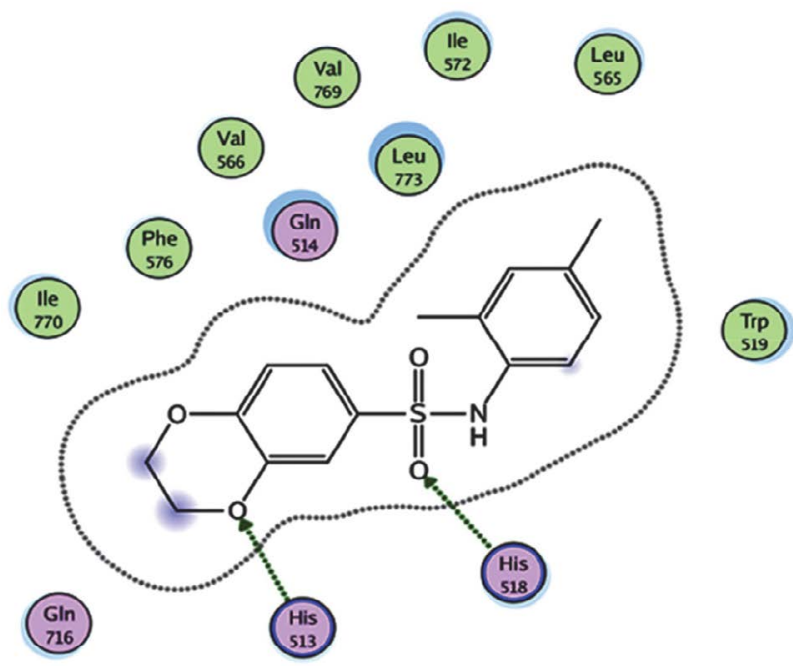

Figure 4: $2 \mathrm{D}$ interaction of $N$-(2,4-dimethylphenyl)-2,3-dihydrobenzo[1,4]dioxine-6-sulfonamide (3b) against lipoxygenase. pound. Tyr121 developed links with the one oxygen of $\mathrm{SO}_{2}$ group in sulfonamide moiety and Ser122 interacted with the one oxygen atom (at fourth position) of 1,4-dioxane ring (Figure 5). Whereas in compound $\mathbf{3 b}$ His518 has developed interactions with oxygen of sulfamoyl group and His513 has interacted with oxygen of the dioxane functionality (Figure 4 ).

\section{Conclusion}

A new series of sulfonamides bearing 1,4-benzodioxane ring systems were synthesized. These were characterized by IR, ${ }^{1} \mathrm{H}$ NMR and EIMS. All the compounds were screened for their antibacterial and antifungal activity by disc diffusion method. Compounds $3 \mathbf{e}, \mathbf{7 b}$ and $7 \mathbf{c}$ exhibited good antimicrobial activity among all the synthesized compounds but lower than that of the standard drug streptomycin. Compound $\mathbf{7 b}$ was better inhibitor against BchE and 7d for AchE, while 3d exhibited good inhibition potential against LOX. Most of the synthesized compounds exhibited an overall bearable toxicity level and could be utilized as possible therapeutic entrants after making structural modifications.

\section{Acknowledgements}

The authors extend their appreciation to the Higher Education Commission of Pakistan for financial support.

\section{Conflict of Interest:}

Authors declare no conflict of interest.

\section{References}

1. C. T. Supuran, Expert Opin. Drug Discov. 2017, 12, 61-88. DOI:10.1080/17460441.2017.1253677.

2. F. Carta, C. T. Supuran, A. Scozzafava, Future Med. Chem. 2014, 6, 1149-1165. DOI:0.4155/fmc.14.68.

3. A. Scozzafava, T. Owa, A. Mastrolorenzo, C. T. Supuran, Curr. Med. Chem. 2003, 10, 925-953.

DOI:10.2174/0929867033457647.

4. C. Capasso, C. T. Supuran, J. Enzym. Inhib. Med. Chem. 2014, 29, 379-387. DOI:10.3109/14756366.2013.787422.

5. F. Carta, A. Scozzafava, C. T. Supuran, Expert Opin. Ther. Pat. 2012, 22, 747-758. DOI:10.1517/13543776.2012.698264.

6. C. Capasso, C. T. Supuran, J. Enzym. Inhib. Med. Chem. 2015, 30, 325-332. DOI:10.3109/14756366.2014.910202.

7. C. Capasso, C. T. Supuran, Expert Opin. Ther. Targets. 2015, 19, 1689-1704. DOI:10.1517/14728222.2014.991312.

8. V. M. Varagic, M. P. Milosevic, Farmakologija, Elitmedica, Beograd. 2009, 622-627.

Figure 5: 2D image of compound $N$-(2,6-dimethylphenyl)- $N$-ethyl-2,3-dihydro- benzo[1,4]dioxine-6-sulfonamide (7d) against acetylcholinesterase.
9. A. Scozzafava, C. T. Supuran, F. Carta, Expert Opin. Ther. Pat. 2013, 23, 725-735. DOI:10.1517/13543776.2013.790957. 
10. A. Casini, A. Scozzafava, C. T. Supuran, Expert Opin. Ther. Pat. 2002, 12, 1307-1327. DOI:10.1517/13543776.12.2.217.

11. F. Carta, C. T. Supuran, Expert Opin. Ther. Pat. 2013, 23, 681691. DOI:10.1517/13543776.2013.780598.

12. C. T. Supuran, J. Enzym. Inhib. Med. Chem. 2016, 31, 345360. DOI:10.3109/14756366.2015.1122001.

13. A. E. Boyd, Diabetes. 1988, 37, 847-850. DOI:10.2337/diab.37.7.847.

14. T. H. Maren, Annu. Rev. Pharmacol. Toxicol. 1976, 16, 309327. DOI:10.1146/annurev.pa.16.040176.001521.

15. C. T. Supuran, Metabolites. 2017, 7, 48-61. DOI:10.3390/metabo7040056.

16. F. Abbate, J. Y. Winum, B. V. L. Potter, A. Casini, J. L. Montero, A. Scozzafava, C. T. Supuran, Bioorg. Med. Chem. Lett. 2004, 14, 231-234. DOI:10.1016/j.bmcl.2004.07.087.

17. L. Puccetti, G. Fasolis, D. Vullo, Z. H. Chohan, A. Scozzafava, C. T. Supuran, Bioorg. Med. Chem. Lett. 2005, 15, 3096-3101. DOI:10.1016/j.bmcl.2005.04.055.

18. F. Carta, L. D. C. Mannelli, M. Pinard, C. Ghelardini, A. Scozzafava, R. McKenna, C. T. Supuran, Bioorg. Med. Chem. 2015, 23, 1828-1840. DOI:10.1016/j.bmc.2015.02.027.

19. H. Nikoofard, M. Sargolzaei, F. Faridbod, Acta. Chim. Slov. 2017, 64, 842-848. DOI:10.17344/acsi.2017.3357.

20. M. A. Abbasi, G. Hussain, Aziz-ur-Rehman, S. Z. Siddiqui, S. A. A. Shah, M. A. Lodhi, F. A. Khan, M. Ashraf, Qurat-ulAin, I. Ahmad, R. Malik, M. Shahid, Z. Mushtaq, Acta. Chim. Slov. 2017, 64, 159-169. DOI:10.17344/acsi.2016.2986

21. A. Weber, A. Casini, A. Heine, D. Kuhn, C. T. Suparan, A. Scozzafava, G. Kelebe, J. Med. Chem. 2004, 47, 550-557. DOI:10.1021/jm030912m.

22. C. T. Suparan, F. Brigani, S. Tilli, W. R. Chegwidden, A. Scozzafava, Bioorg. Med. Chem.2001, 9, 703-714.

DOI:10.1016/S0968-0896(00)00288-1.

23. M. A. R. Matos, C. C. S. Sousa, V. M. F. Morais, J. Phys. Chem. A. 2008, 112, 7961-7968.

24. Y. Luo, S. Zhang, K. M. Qiu, Z. J. Liu, Y. S. Yang, J. Fu, W. Q. Zhong, H. L. Zhu, Bioorg. Med. Chem. Lett. 2013, 23, 10911095. DOI:10.1016/j.bmcl.2012.12.010.
25. J. Sun, Y. S. Yang, W. Li, Y. B. Zhang, X. L. Wang, J. F. Tang, H. L. Zhu, Bioorg. Med. Chem. Lett. 2011, 21, 6116-6121. DOI:10.1016/j.bmcl.2011.08.039.

26. J. Sun, N. Cao, X. M. Zhang, Y. S. Yang, Y. B. Zhang, X. M. Wang, H. L. Zhu, Bioorg. Med. Chem. 2011, 19, 4895-4902. DOI:10.1016/j.bmc.2011.06.061.

27. Y. Harrak, G. Rosell, G. Daidone, S. Plescia, D. Schillaci, M. D. Pujol, Bioorg. Med. Chem. 2007, 15, 4876-4890.

DOI:10.1016/j.bmc.2007.04.050.

28. Y. Aiba, D. Hasegawa, T. Marunouchi, K. Nagasawa, H. Uchiro, S. Kobayashi, Bioorg. Med. Chem. Lett. 2001, 11, 27832786. DOI:10.1016/S0960-894X(01)00561-3.

29. M. Z. Xu, W. S. Lee, J. M. Han, H.W. Oh, D.S. Park, G.R. Tian, T.S. Jeong, H.Y. Park, Bioorg. Med. Chem. 2006, 14, 78267834. DOI:10.1016/j.bmc.2006.07.063.

30. M. T. Vazquez, G. Rosell, M. D. Pujol, Eur. J. Med. Chem. 1997, 32, 529-534. DOI:10.1016/S0223-5234(97)84016-0.

31. I. A. Guedes, C. S. Magalhaes, L. E. Dardenne, Biophys. Rev. 2014, 6, 75-87. DOI:10.1007/s12551-013-0130-2.

32. M. Irshad, M. A. Abbasi, Aziz-ur-Rehman, S. Z. Siddiqui, M. S. Ali, M. Ashraf, T. Ismail, I. Ahmad, S. Hassan, M. A. Lodhi, S. B. Jamal, Pak. J. Pharm. Sci. 2016, 29, 1913-1925.

33. G. L. Ellman, K. D. Courtney, V. Andres, R. M. Featherstone, Bio. Pharm. 1961, 7, 88-95.

DOI:10.1016/0006-2952(61)90145-9.

34. A. L. Tappel, Arch. Biochem. Biophys. 1953, 44, 378-395.

35. S. Baylac, P. Racine, Int. J. Aromather. 2003, 13, 138-142. DOI:10.1016/S0962-4562(03)00083-3.

36. A. T. Evans, Biochem. Pharmacol. 1987, 36, 2035-2037. DOI:10.1016/0006-2952(87)90505-3.

37. M. Kaspady, V. K. Narayanaswamy, M. Raju, G. K. Rao, Lett. Drug Des. Discov. 2009, 6, 21-28.

DOI:10.2174/157018009787158481.

38. P. Sharma, J. D. Sharma, J. Ethnopharmacol. 2001, 74, 239243. DOI:10.1016/S0378-8741(00)00370-6.

39. W. A. Powell, C. M. Catranis, C. A. Maynard, Lett. Appl. Microbiol. 2000, 31, 163-168.

DOI:10.1046/j.1365-2672.2000.00782.x.

40. M. J. Bostro, J. R. Greenwood, J. Gottfries, Mol. Graph. Model. 2003, 21, 449-462. DOI:10.1016/S1093-3263(02)00204-8.

\section{Povzetek}

V predstavljenem raziskovalnem delu poročamo o seriji $N$-aril-2,3-dihidrobenzo[1,4]dioksin-6-sulfonamidov 3 in njihovih novih $N$-substituiranih derivatih 6 in 7, ki smo jih iz 3 pripravili z benzil kloridom oz. etil jodidom. Sintezo smo izvedli v več stopnjah. Strukture produktov smo določili z ${ }^{1} \mathrm{H}$ NMR, IR in EIMS spektroskopskimi tehnikami. Kot encime smo v študiji uporabili butirilholinesterazo (BChE), acetilholinesterazo (AChE) in lipoksigenazo (LOX). Ugotovili smo, da večina spojin izkazuje zmerno aktivnost proti BChE in AChE in obetavno dobro aktivnost proti lipoksigenazi. Med matičnimi sulfonamidi so $\mathbf{3 a}, \mathbf{3 b}, \mathbf{3} \mathbf{c}$ in $\mathbf{3 e}$ izkazali najbolj učinkovite antimikrobne aktivnosti, po drugi strani pa so derivati $\mathbf{6 a}, \mathbf{6 c}, \mathbf{7 a}, \mathbf{7 b}$ in $\mathbf{7 c}$ izkazali dobro aktivnosti proti izbranim bakterijam in glivam. Hemolitsko aktivnost smo določili, da bi ugotovili morebitno terapevtsko uporabnost pripravljenih spojin. Vse spojine smo tudi računsko sidrali v encime LOX, BChE in AChE. 